NBER WORKING PAPER SERIES

\title{
EXPLOITING MIT SHOCKS IN HETEROGENEOUS-AGENT ECONOMIES: THE IMPULSE RESPONSE AS A NUMERICAL DERIVATIVE
}

\author{
Timo Boppart \\ Per Krusell \\ Kurt Mitman \\ Working Paper 24138 \\ http://www.nber.org/papers/w24138 \\ NATIONAL BUREAU OF ECONOMIC RESEARCH \\ 1050 Massachusetts Avenue \\ Cambridge, MA 02138 \\ December 2017
}

Boppart thanks Vetenskapradet (grant 2016-02194) for financial support. Krusell thanks the Knut and Alice Wallenberg Foundation for financial support. MITman thanks the European Research Council (ERC Starting Grant 759482) and the Ragnar Soderbergs Stiftelse for financial support. The views expressed herein are those of the authors and do not necessarily reflect the views of the National Bureau of Economic Research.

NBER working papers are circulated for discussion and comment purposes. They have not been peer-reviewed or been subject to the review by the NBER Board of Directors that accompanies official NBER publications.

(C) 2017 by Timo Boppart, Per Krusell, and Kurt Mitman. All rights reserved. Short sections of text, not to exceed two paragraphs, may be quoted without explicit permission provided that full credit, including $\left({ }^{\circ}\right.$ notice, is given to the source. 
Exploiting MIT Shocks in Heterogeneous-Agent Economies: The Impulse Response as a Numerical Derivative

Timo Boppart, Per Krusell, and Kurt Mitman

NBER Working Paper No. 24138

December 2017

JEL No. C68,E1

\section{ABSTRACT}

We propose a new method for computing equilibria in heterogeneous-agent models with aggregate uncertainty. The idea relies on an assumption that linearization offers a good approximation; we share this assumption with existing linearization methods. However, unlike those methods, the approach here does not rely on direct derivation of first-order Taylor terms. It also does not use recursive methods, whereby aggregates and prices would be expressed as linear functions of the state, usually a very high-dimensional object (such as the wealth distribution). Rather, we rely merely on solving nonlinearly for a deterministic transition path: we study the equilibrium response to a single, small "MIT shock" carefully. We then regard this impulse response path as a numerical derivative in sequence space and hence provide our linearized solution directly using this path. The method can easily be extended to the case of many shocks and computation time rises linearly in the number of shocks. We also propose a set of checks on whether linearization is a good approximation. We assert that our method is the simplest and most transparent linearization technique among currently known methods. The key numerical tool required to implement it is value-function iteration, using a very limited set of state variables.

Timo Boppart

Institute for International Economic Studies

Stockholm University

SE-106 91 Stockholm

Sweden

timo.boppart@iies.su.se

Per Krusell

Institute for International Economic Studies

Stockholm University

10691 STOCKHOLM

SWEDEN

and NBER

per.krusell@iies.su.se
Kurt Mitman

Institute for International Economic Studies

Stockholm University

10691 Stockholm

SWEDEN

kurt.mitman@iies.su.se 


\section{Introduction}

In this paper we propose a new and simple linearization method for analyzing frameworks with consumer heterogeneity and aggregate shocks. We apply it in the context of an otherwise standard real business cycle model with two kinds of technology shocks: those that are neutral, as in Kydland and Prescott (1982), and those that are investment-specific, as in Greenwood, Hercowitz, and Krusell (2000). Our main goal is to show how the method works but we also consider the simplest type of potentially stabilizing fiscal policy for a version of our environment, namely, countercyclical budget deficits (financed by lumpsum transfers). The method we propose is very straightforward and therefore, we hope, significantly easier to use than many existing methods - it is accessible even to advanced undergraduates in economics. In this introduction, we begin with a brief motivation for including household heterogeneity in macroeconomic analysis. We then provide a quick summary of the core features of the method and turn to the model setting and policy analysis.

\subsection{Why an interest in heterogeneity?}

Recently, the literature on business cycles and stabilization has placed an increasingly heavy emphasis on heterogeneity across households in a variety of characteristics: wealth, earnings, and more. Whence comes this new emphasis in macroeconomics? There are several types of answers. One type of answer relies on the effect inequality has on macroeconomic aggregates. In the economic realm, there is now increasing evidence that the marginal propensities to make decisions that are central for households-regarding consumption (in total as well as in terms of its structure), hours worked, and investments in various forms of assets - vary quite substantially in the population; see, for example, the findings in Johnson, Parker, and Souleles (2004) who provided evidence on the departure from the permanent income hypothesis, and Misra and Surico (2014) for estimating the heterogeneity in responses across households. This basic evidence has potentially sharp implications for macroeconomic aggregates. Policy makers thus need to know how their proposed instruments affect different subgroups, as seemingly similar policies may actually 
have radically different effects (policies that are identical in a representative-agent model are often not under heterogeneous agents). Thus, the use of representative-agent models in macroeconomic theorizing runs the risk of overlooking these important channels. In particular, a given policy action can be either more or less potent than what is predicted from such a representative-agent model. The rapidly expanding literature on heterogeneousagent modeling can likely be attributed in large part due to these arguments.

One might also worry, as elaborated on in Piketty (2014), that extreme inequality can lead to social unrest and even threaten our democratic institutions. That is, there is a political realm too where inequality affects the macroeconomy. A different way of expressing this point, along the lines of the argument above, is that the marginal propensities relevant in political decisions - voting and political activities more generally —also vary within the distribution. The point that the wealth distribution influences aggregate policy, like taxes, via dispersed political preferences is since long established (see, e.g., Downs, 1957, and Meltzer and Richard, 1981) but the broader implications for the smooth workings of democracy are now increasingly emphasized. There is an older macro-and-political economy literature formalizing the tax-distribution channel (see, e.g., Persson and Tabellini, 1994, and Alesina and Rodrik, 1994, as well as Krusell and Ríos-Rull, 1999) but the broader connection is less explored.

A second type of argument for the focus on inequality is simply that there is an increasing interest in it per se, perhaps because we have social preferences displaying inequality aversion. In addition, economists and policymakers may be interested in understanding the distributional consequences of aggregate shocks. For example, a small aggregate decline in hours may mask substantial heterogeneity in unemployment risk across individuals. Regardless of any potential taste for redistribution, it seems important for macroeconomists not just to work out the aggregate consequences of different shocks and policy options but also their distributional impacts.

A third type of argument, that is related to the first one but also more general in nature, is that the representative-agent nature of most of macroeconomic modeling, like any other assumption, needs to be examined from a robustness perspective. Clearly, people 
in the real world are heterogeneous in many dimensions and how well the representativeagent model approximates the aggregate behavior of a more diverse population really is a very open question. ${ }^{1}$ That is, the focus on heterogeneity can simply be viewed as an effort at examining the robustness (and perhaps inappropriateness) of the benchmark model. This endeavor has been ongoing but has been challenging due to the difficulties involved in solving dynamic models with consumer heterogeneity, especially models with aggregate shocks. Krusell and Smith (1998) is a step forward here, as are a number of other papers, including Den Haan (1997), Ríos-Rull (2001), Reiter (2009, 2010), Ahn et al. (2017), and many others; the present paper follows in the footsteps of especially the three latter papers. Many of the methods that have been proposed were perhaps once upon a time demanding in terms of computer processing time or numerical knowledge investments but these challenges are now much less daunting. As a result, in our view, computational difficulty should no longer be a primary excuse for applied macroeconomists in abstracting from heterogeneity in modeling when such heterogeneity is plausibly important for the workings of policy; after all, imagine if engineers had this attitude when constructing buildings, bridges, or airplanes. At the same time, we must continue pushing forward in terms of providing even better and more easy-to-use tools-just like in engineering science - and the present paper is one such effort. In the case of heterogeneous-agent economies with aggregate uncertainty, all the available methods rely on some sort of approximation, moreover, so it seems valuable to have an arsenal of different methods, thus justifying "engineering-style" work along several parallel lines.

\subsection{The method}

As mentioned above, the literature has provided us with number of tools and techniques to numerically solve models with heterogeneity and aggregate shocks. These methods can be used for the models we discuss in the present paper. However, the tools we develop here are, we think, particularly simple to use and intuitive. We especially hope that

\footnotetext{
${ }^{1}$ When macroeconomic theory is criticized by researchers from other areas within economics, the representative-agent assumption may be the most commonly mentioned point. When it comes to communicating with non-economists how macroeconomic textbook models work, it, of course, is even harder to motivate the representative-agent assumption; it is often best to simply not mention it.
} 
they can become valuable for analyzing fiscal and monetary policy rules and their welfare implications for different subgroups of consumers. However, as for how useful and accurate our method will be, of course, remains to be seen. As is typically the case in computational economics, the most suitable method really varies depending on the specific model to be solved and economic question to be answered. We will therefore not aim to make a general method evaluation here, but merely present the key ideas and apply it in a set of simple examples. It should be noted that although our setting is very standard and closely related to the setting in Krusell and Smith (1998) and that studied in the JEDC volume referred to below, its benchmark does allow two continuously-valued shocks along with valued leisure.

The key idea is to come up with an easy-to-use linearization technique. Linearization techniques of different sorts have been developed in a number of applications. The first complete such contributions were provided in Michael Reiter's work (Reiter, 2009 and 2010), but early approaches were also explored by a number of other economists, including Jeff Campbell, Hess Chung, Stefan Krieger, and Marcelo Veracierto. Current, rather advanced, linearization techniques include Ahn et al. (2017), which provides a very ambitious and general toolbox based on the authors' previous work, and David Childers' recent paper (Childers, 2017). In all these approaches, the linearization approach relies on taking derivatives analytically along the lines of a Taylor expansion. In contrast we do not compute analytical derivatives. More importantly, unlike ours, the standard approach is built on recursive methods whereby aggregates and prices are expressed as (to be linearized) functions of the state. The state is usually a very high-dimensional object-involving at a minimum the distribution of wealth across agents, an infinite-dimensional object - and therefore potentially quite challenging to even describe, let alone linearize with respect to. There are also many ways of constructing such a linearization and its law of motion. The approach we follow here uses recursive techniques for solving the households' problems but not for describing aggregates. Rather, we base our linearization on a nonlinearly obtained solution for a deterministic transition path to an "MIT shock". An "MIT shock" is an unexpected shock that hits an economy at its steady state, leading to a transition 
path back towards the economy's steady state. We study a single, small "MIT shock" carefully, and then linearize directly using the computed impulse response. We thus consider this impulse response as a numerically computed derivative of the effect of an initial (infinitesimal) shock on the variable in question at different time horizons.

As is typical, the linearization will be performed around a steady state. ${ }^{2}$ Hence, in a first step we solve for a steady state with entirely standard, and fully nonlinear, methods. We then study a deviation from this steady state and a transition back to it. Consider for example a shock to aggregate TFP, which we denote by $z$ and which, in the economy with aggregate shocks, follows an $\operatorname{AR}(1)$ process in logs with a serial correlation parameter $\rho$. Thus, (the log of) the shock will go up by, say, one unit in period 0 and thus delivers the full sequence of values $\left(1, \rho, \rho^{2}, \rho^{3}, \ldots\right)$. When we solve for our resulting deterministic equilibrium transition path, we consider a dynamic-programming version of the household's problem where the state variable consists of the individual's own states (asset holdings and an income shock in our simple model, as in Aiyagari, 1994) and, importantly, time. The appearance of time captures how aggregates affect the individual: the individual takes as given a sequence of prices and because it is irrelevant for the individual how these prices are determined, they can be summarized as depending simply on time. Notice that they will not involve aggregate uncertainty since we consider a deterministic path. The computation of the deterministic equilibrium path is straightforward: it uses entirely standard methods. In particular, we guess on a price path (or the path for an aggregate variable like consumption), solve the household's problem backwards - given that we know that there will be convergence back to the same steady state - and then derive the aggregate implications of the households' behavior and update our guess for the price path. This iterative procedure is also standard and fully nonlinear.

The result of having computed the nonlinear transition path for the heterogeneousagent economy is a time path for all aggregate statistics: output, consumption, investment, prices, and the entire wealth distribution (as well as labor supply if considered as endoge-

\footnotetext{
${ }^{2}$ As all methods that rely on linearization, our method imposes certainty equivalence. Then, the variables in the non-stochastic steady state will by assumption coincide with the ergodic mean of those of the stochastic economy.
} 
nous). ${ }^{3}$ So let us focus on a generic such aggregate statistic; we label it $x$, and we have thus obtained a sequence $\left\{x_{0}, x_{1}, x_{2}, \ldots\right\}$. Now consider the same economy subjected to recurring aggregate shocks to $z$. The key idea behind the procedure we use to compute equilibria in the aggregate-shocks economy is that we can, and do, regard the $x$ sequence in response to the one-time shock in the aggregate technology variable $z$ (and exponential convergence back to its mean) as well approximated by a linear system. (The shock appears in a multiplicative way an hence we linearize in the logarithm of the variables.) A linear system would precisely mean that the effects of shocks are linearly scalable and additive so that the level of $x$ at some future time $T$, after a sequence of random shocks is simply $x_{0} \epsilon_{z, T}+x_{1} \epsilon_{z, T-1}+x_{2} \epsilon_{z, T-2}+\ldots$, where $\epsilon_{z, t}$ is the innovation to (the logarithm of) $z$ in period $t$. Thus, our model with aggregate shocks can be obtained by mere simulation based on the one deterministic path - the non-linear impulse response function-we obtained.

It is instructive to compare our method with the recursive linearization methods in the literature referred to above. In essence, those techniques construct (i) a linear mapping from $(\log ) z$ and some summary description of the aggregate state (such as a set of moments of the wealth distribution) to $x$ and then (ii) a resulting linear law of motion for the summary of the aggregate state. But this delivers precisely a linear system that, in reduced form, gives our simple $x_{0} \epsilon_{z, T}+x_{1} \epsilon_{z, T-1}+x_{2} \epsilon_{z, T-2}+\ldots$, so in this sense the intermediate steps (i) and (ii) are not needed if one can obtain $\left\{x_{0}, x_{1}, x_{2}, \ldots\right\}$, which we do with our nonlinear method.

Linearity of a dynamic system allows for very powerful generalizations. First, we can look at any outcome variable. For example, our transition-path equilibrium delivers the evolution for any distributional statistic, so $x$ could be, say, the 3rd percentile of the wealth distribution. Second, one can incorporate more kinds of aggregate shocks easily: computation time rises linearly in the number of independent shocks. In the case of two shocks, a $z$ and a $q$ shock, one would simply compute two transition-path equilibria, one for a period-0 deviation of $z$ from its steady-state value and then a similar one for $q$. Then,

\footnotetext{
${ }^{3}$ Of course, individual agents move stochastically within this distribution due to idiosyncratic income shocks, but these wash out in the aggregate.
} 
given the linearity, the effects of the two shocks are simply additive: the final effect on $x$ in period $T$ is $x_{0}^{z} \epsilon_{z, T}+x_{0}^{q} \epsilon_{q, T}+x_{1}^{z} \epsilon_{z, T-1}+x_{1}^{q} \epsilon_{q, T-1}+x_{2}^{z} \epsilon_{z, T-2}+x_{2}^{q} \epsilon_{q, T-2}+\ldots$, where $\epsilon_{q, t}$ is the innovation to (the logarithm of) $q$ in period t.

A virtue of the linearization method compared to that in Krusell and Smith (1998) is that the case with valued leisure can be computed in a more straightforward manner. In such a model, as in most cases where there is a nontrivial market-clearing condition each period, ${ }^{4}$ Krusell and Smith (1998) argue that it is necessary to use a two-step procedure: each period during a simulation, a price (the wage in this case) needs to be iterated on so as to achieve exact market clearing, and hence a supply function (for labor) of this static price needs to be computed. This supply function is obtained from consumer maximization where future prices are taken as given functions of the future aggregate state but the current price can deviate from such a rule. ${ }^{5}$ In the linearization method here, no extra complication arises if there are nontrivial market-clearing conditions each period.

We must also emphasize that the key numerical tool used to implement our method - if not the only tool - is value-function iteration. Value-function iteration is used for solving the consumer's problem in a steady-state equilibrium. This value-function iteration involves a small set of state variables (an exogenous idiosyncratic shock and capital, in our application). Value-function iteration is then used again in solving for the transition path, now backwards over time, so time is the only additional state variable here and the iteration involves only a number of steps equal to the number of time periods until the new steady state is reached. In the former case, there is an outer layer of iterations over the steady-state interest rate and in the latter case the iteration is over a sequence of interest rates, but there is no additional conceptual difference between the two cases. Hence, solving for a transition path is really very similar to solving for a steady state.

Is the equilibrium we compute accurate? That is, is our linearization an accurate method for the economy at hand? Given that a distance measure between the computed

\footnotetext{
${ }^{4}$ In the baseline Krusell and Smith model without valued leisure both the capital stock and aggregate hours are predetermined along any simulation path, such that the output market trivially will clear given the wage and interest rate from the firm's problems. Along simulation paths households may be making forecast errors about next period's capital stock, but contemporaneous prices always clear the market.

${ }^{5}$ The same complication appears, for example, when one solves an asset pricing model where a bond price needs to be computed each period; see Krusell and Smith (1997).
} 
equilibrium and the true one cannot typically be obtained in this class of models, there is no simple answer. One check that can be performed, however, is to compute transition paths for different initial shock sizes and signs and assess whether the resulting effects on the variables in question ( $x$ in our example) are scalable, as assumed in the linearization method. It may then turn out that significant nonlinearities appear or that the shock responses are not approximately symmetric around zero, in which case non-linear methods are needed. One can design a variety of checks of, such as drawing two consecutive MIT shocks, in period 0 and in period 1, and seeing whether the resulting transition path is close to that obtained as a sum of two consecutive shocks. With two type of shocks $z$ and $q$, one can subject the economy to simultaneous shocks of these variables at time 0 and then compare to the sum of each of the two shocks, and so on.

Finally, one may ask whether linearization does not eliminate some important mechanisms in a heterogeneous-agent economy, such as the nontrivial evolution of the wealth distribution over time and its effects on aggregates. It does not: it includes all the mechanisms (to a first order). For example, an aggregate shock will influence outcomes in a manner taking into account the distribution of marginal propensities to consume and work, and the evolution of this distribution will itself be solved for; linearization does not set these effects to zero but merely consider their first-order elements. ${ }^{6}$

\footnotetext{
${ }^{6}$ To be more concrete, consider an alternative model that will have similar features: one with two agents with a common utility function $u(c)$, no idiosyncratic shocks and unrestricted borrowing and lending, but unequal wealth between the two agents. Then the equilibrium laws of motion will be given by the function $H$ such that $A_{1}^{\prime}=H\left(A_{1}, A_{2}, z\right)$ and $A_{2}^{\prime}=H\left(A_{2}, A_{1}, z\right)$ and output will be given by $y=G\left(A_{1}, A_{2}, z\right)$, where $A_{i}$ denotes the wealth of agent $i, y$ output, and $z$ an exogenous shock; a prime denotes the variable's value the following period. Because $A_{1}+A_{2}=k$, the aggregate capital stock, we have $G\left(A_{1}, A_{2}, z\right)=\tilde{G}\left(A_{1}+A_{2}, z\right)$. Now consider how $y_{t+m}$ will change for $m>1$ in response to a change in $\log z_{0}$. Linearization means that we will identify $\frac{d y_{t+m}}{d \log z_{0}}$ based only on the first-order effects, i.e., $\tilde{G}_{1}\left(A_{1, t+m}+A_{2, t+m}, z_{t+m}\right) H_{1}\left(A_{1, t+m-1}, A_{2, t+m-1}, z_{t+m}\right) \frac{d A_{1, t+m-1}}{d \log z_{0}}+\tilde{G}_{1}\left(A_{1, t+m}+\right.$ $\left.A_{2, t+m}, z_{t+m}\right) H_{1}\left(A_{2, t+m-1}, A_{1, t+m-1}, z_{t+m}\right) \frac{d A_{2, t+m-1}}{d \log z_{0}}+\tilde{G}_{2}\left(A_{1, t+m}+A_{2, t+m}, z_{t+m}\right) \frac{d z_{t+m}}{d \log z_{0}}$. If preferences aggregate, $H_{1}=H_{2}$ for all values of the arguments, and then it is easy to show that the first two terms of this expression are identical and thus collapse. If not, however, the evolution of the wealth distribution will evolve nontrivially, and it will nontrivially affect equilibrium outcomes. Thus, despite a lack of aggregation the linearization method does captures the effects going through an unequal and evolving wealth distribution. This argument is general and can in particular be applied in our context, where there is also a lack of aggregation.
} 


\subsection{The model}

The model we look at is a standard Aiyagari (1994) economy, augmented to include valued leisure, with two kinds of aggregate shocks: an input-neutral technology shock and an investment-specific technology shock. Consumers face idiosyncratic labor productivity risk against which they cannot insure directly but they can accumulate precautionary savings. For this model, no aggregation theorem is available: the whole distribution of asset holdings among consumers matters for determining aggregate capital accumulation and for total hours worked, because the marginal propensities to save (and work) differ across consumers. In particular, more wealthy consumers are better insured and have higher marginal propensities to save and lower marginal propensities to work. The consumption function is not linear either and is not necessarily concave.

We briefly look at a formulation of the model with a "demand externality" in the form of a reduced-form pure externality on TFP from aggregate consumption. In particular, if consumption rises, so does TFP. The interpretation is that of utilization of the input factors and the motivation comes from the recent work by Bai, Ríos-Rull, and Storesletten (2016). The difference being that our demand channel amounts to a market failure; whereas those authors describe a search market with price posting, which yields efficient outcomes.

We illustrate the failure of aggregation by showing that Ricardian equivalence does not hold: we look at a transfer policy with a stable rule for government bonds involving deficits when consumption is below steady state.

\subsection{Outline}

We begin by describing the model in Section 3. We then briefly describe our computational approach in Section 4 after which we show our results in Section 5. In the latter section we also discuss accuracy of linearization based on looking at transition paths with different sizes and signs of the initial shock. We conclude in Section 6. 


\section{Numerical methods in macroeconomics: a mini-history}

In this section we provide some relevant background in the form of a very brief history of numerical methods used in dynamic macroeconomics for the purpose of producing "quantitative macroeconomic theory", i.e., theory restricted to match relevant microeconomic data and other facts, such as long-run trends. The specific aim here is to make connections between the method we propose in the present paper and earlier methods and concepts; that is, we do in no way aim to accurately reflect the whole literature on solving dynamic macroeconomic models. We discuss representative-agent models and how they have been solved first.

\subsection{Representative-agent models}

We begin by noting that prior to the path-breaking work by Kydland and Prescott (1982), researchers had used analytical methods to characterize perfect-foresight equilibria that were the result of "MIT shocks". An MIT shock, a term coined by Tom Sargent, refers to an unpredictable shock to the steady-state equilibrium of an economy without shocks. That is, in this economy no shocks are expected to ever materialize but nevertheless a shock now occurs. The analysis then focuses on understanding the resulting equilibrium transition along a perfect-foresight path, again under the assumption that no shock will ever occur again. Thus, the described procedure seems hard to square with rational expectations. ${ }^{7}$

The Kydland-Prescott paper developed a non-linear model without market frictions and, hence, could focus on solving a planning problem. This problem was approached using "linearization" around the steady state; Kydland and Prescott first solved for the steady state, then provided a quadratic (second-order Taylor expansion) approximation of the objective function - expressed in terms of the vector of choice variables - around that steady state, along with a linear set of (or linearized) constraints. Thus, they obtained a linear-quadratic problem, which was well known to have an exact solution in the form of a

\footnotetext{
${ }^{7}$ The "MIT" qualifier reflects the fact that one or more researchers at MIT used this method. Sargent, at the time of the invention of the term, was at Minnesota; he received his PhD in Cambridge, Mass., but from Harvard.
} 
quadratic value function along with linear policy rules. The paper by King, Plosser, and Rebelo (1988) and its technical appendix (separately published later, see King, Plosser, and Rebelo, 2002) describe this procedure in detail, including how to compute all the endogenous policy and value-function parameters. ${ }^{8}$

A key element in the approach pioneered by Kydland and Prescott was the use of a recursive system, which fits value-function methods well. The key objects sought were thus functions of a state vector of exogenous and endogenous variables. To be concrete, one would for example in the very simplest case of a stochastic growth model with optimal saving and no adjustment costs find output, $y$, to be a function $G$ of the capital stock, $k$, and TFP, $z: y=G(k, z)$. Similarly, the law of motion for the endogenous state would be written using a function $H$ as $k^{\prime}=H(k, z)$. Thus, linearization amounted to finding linear approximations of $G$ and $H$-in the form of vectors. ${ }^{9}$ Once the vectors approximating $G$ and $H$ had been found, the system was simulated by drawing shocks and unconditional moments were computed, such as correlations between macroeconomic variables and their relative percentage standard deviations. The figure below, drawn from Kydland and Prescott (1982), illustrates.

\footnotetext{
${ }^{8}$ As of publication, King, Plosser, and Rebelo's two papers the Kydland-Prescott paper all have thousands of citations. The paper by King, Plosser, and Rebelo (1988) of course made other, distinct contributions, such as finding an explicit class of utility functions that was sufficient and necessary for balanced growth with constant hours worked.

${ }^{9} \mathrm{An}$ alternative method in the literature has been to derive a set of linear stochastic difference equations whose solutions then delivers $G$, when expressed recursively. The solved-out stochastic sequence for capital, in our example, would then satisfy $k_{1}=H\left(k_{0}, z_{0}\right), k_{2}=H\left(H\left(k_{0}, z_{0}\right), z_{1}\right)$, and so on.
} 
TABLE III

Model's Standard Deviations and Correlations with Real OUtPut ${ }^{\mathrm{a}}$

\begin{tabular}{lcc}
\hline Variable & $\begin{array}{c}\text { Standard Deviations: } \\
\text { Means (Standard Deviations) } \\
\text { of Sample Distribution }\end{array}$ & $\begin{array}{c}\text { Correlations with Output: } \\
\text { Means (Standard Deviations) } \\
\text { of Sample Distribution }\end{array}$ \\
\hline Real Output & $1.80(.23)$ & - \\
Consumption & $.63(.09)$ & $.94(.01)$ \\
Investment & $6.45(.62)$ & $.80(.04)$ \\
Inventories & $.89(.06)$ & $-.15(.11)$ \\
Inventories plus & $2.00(.20)$ & $.39(.06)$ \\
Capital Stock & $.63(.08)$ & $-.07(.06)$ \\
Hours & $1.05(.13)$ & $.93(.01)$ \\
$\begin{array}{l}\text { Productivity } \\
\text { Real Interest Rate } \\
\text { (Annual) }\end{array}$ & $.90(.10)$ & $.90(.02)$ \\
\hline
\end{tabular}

aThe length of the sample period both for the model and for the U.S. economy is 118 quarters. ${ }^{\mathrm{b}}$ Measured in per cent.

Quite soon, researchers started examining the numerical accuracy of the solutions obtained with the linear-quadratic approximation method; after all, the underlying model had nonlinear elements of potential quantitative importance. The classic 1990 issue in the Journal of Business and Economic Statistics, edited by John Taylor and Harald Uhlig, collected a number of papers employing linear-quadratic other methods to solve the same underlying model - the stochastic optimizing growth model: see the next figure for the front page. 


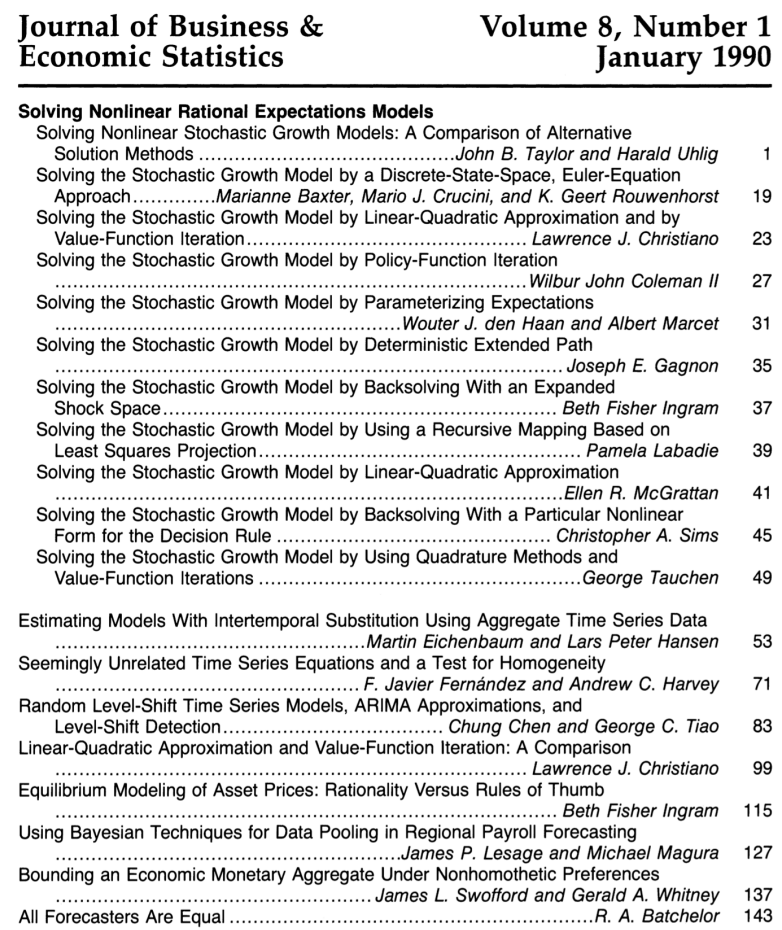

The conclusion from the JBES issue was that nonlinearities simply did not seem to play a very important role in the model under study.

Meanwhile, another development in macroeconomics was taking place whereby VARsvector autoregressions, a tool primarily used for empirical analysis - came to increasing use. The path-breaking paper on this topic, Sims (1980), specified a linear system of equations for macroeconomic aggregates. From the present perspective, such a system can also be derived from the solution to a linear-quadratic model, which researchers soon realized. This meant, in particular, that estimated VARs became a convenient tool for comparing model to data: one compared the model-generated VAR to that estimated in the data, the result of which became known as "structural VARs", whereby some model parameters were estimated directly using a VAR, either with classical or Bayesian econometrics.

But more importantly from the present perspective, VARs propelled the use of impulse response functions, IRFs in quantitative macroeconomic theory: the use of the linear system to trace out the path for an endogenous variable in response to an exogenous 
shock at an initial point in time. Using a purely empirical VAR, one would identify exogenous shocks - such as one to technology - along with their autocorrelation properties and then evaluate how an endogenous variable, like output, would behave over time in response to a shock innovation at time zero. Using the linear system obtained as an approximation to the optimal policy rules at a steady state of the theoretical model one can also generate an IRF (and the two IRFs can be compared - an alternative data-model comparison to that of using the unrestricted VAR system); a typical example from the literature of model-generated IRFs is shown in the figure below (countless papers display such multi-box graphs, especially in the monetary literature).

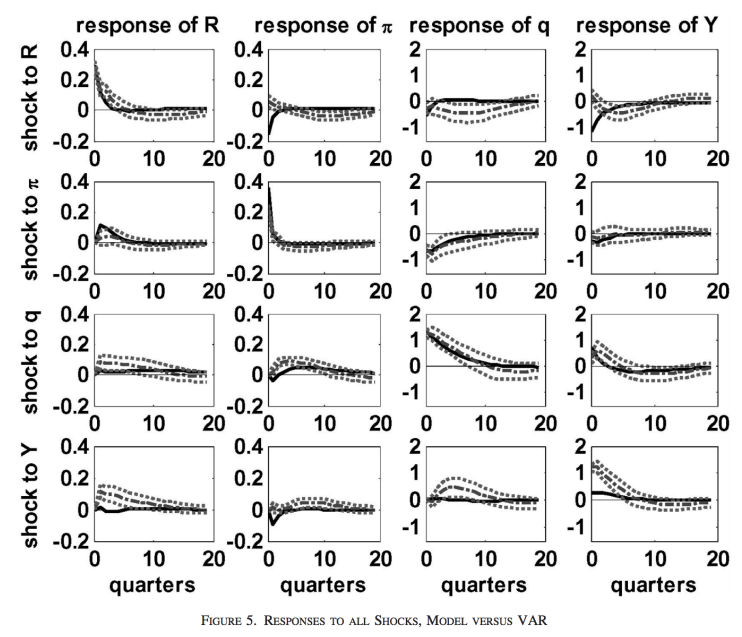

The key about an IRF here is that it can be viewed as a response to an MIT shock: let the economy be in steady state, expose it to an "unexpected" shock and work out how the endogenous variables will behave over time in a rational-expectations equilibrium under the assumption that no other shocks materialize. The rational-expectations part sounds contradictory, again, but is not: in a linear-quadratic model, certainty equivalence holds, i.e., the coefficients of the linear policy rules do not depend on the second-order moments of the shock processes. This means, in particular, that an IRF can be viewed as the average (conditionally expected) path of an endogenous variable, thus integrating in this expectations operator across outcomes of all future shocks (given the initial shock). Thus, the perfect-foresight response to an unexpected shock conditional on no other shocks 
occurring coincides with the average response to a shock of the same size that was expected (in the sense that it had a zero expected mean but a positive variance) and that is later followed by other shocks. Hence, the linearity of the basic models made MIT shocks turn out to be really useful!

Approximate linearity was then used to compute equilibria in a very broad set of business-cycle models, including those with price and wage stickiness. Thus, packages like Dynare or Uhlig's Toolkit became ubiquitous in research as well as teaching; it is probably not an understatement to say that this development revolutionized quantitative macroeconomic theory. These packages ask the researcher to input the model's dynamic equations in their non-linear form and then automatically offer (i) a calculation of the steady state; (ii) the (linear) equilibrium decision rules; (iii) the corresponding impulse response functions; and (iv) an estimation routine. It should be noted that in many (most?) of the applications in the literature there was no separate check that a linear approximation is indeed accurate.

For some questions, the linear-quadratic approximation is not useful; one example is asset pricing or portfolio choice, where higher moments of the shocks are at the core of the analysis. Similarly, in models where non-linearities are believed to play a central role, it is also crucial to use other methods. Here, researchers have explored different paths; one is to use one out of a variety of the general non-linear approaches (of which several were applied in the Taylor-Uhlig volume referred to above) and another path was to develop second-order perturbation methods; see, e.g., Judd and Guu (1997) or Schmitt-Grohé and Uribe (2004).

\subsection{Heterogeneous-agent models}

The numerical analysis of models with heterogeneous consumers and uninsurable idiosyncratic shocks started with papers by Imrohoroglu (1989), in a partial-equilibrium case, and Huggett (1993) and Aiyagari (1994) in general equilibrium. Given that borrowing constraints and uninsurability were central features in these models, it was impossible 
to avoid non-linear methods for solving the consumers' problems. ${ }^{10}$ Thus, these papers, which defined and computed steady states, employed value-function iteration, much as in some of the contributions to the JBES volume, now applied at the individual level. In Huggett's and Aiyagari's work, the price-determination algorithm worked as follows: (i) the agent's dynamic programming problem is first solved using non-linear methods based on a guess on a set of prices (such as the steady-state interest rate); (ii) the decision rules are then aggregated to check market clearing in the steady state; (iii) and, in case markets do not clear, an update on the price(s) is computed and the procedure is repeated until markets do clear.

A steady-state equilibrium in the heterogeneous-agent economy under study in these papers consists (aside from decision rules and value functions solving the consumers' problems) of a small set of prices or aggregate variables (one, in each of the cases of Huggett, 1993, and Aiyagari, 1994) and a stationary distribution of consumers, within which there are idiosyncratic movements but whose aggregate moments are all constant. The algorithm described has proven to work for a large number of applications. It should be noted here in this context that a reason why these steady-state equilibria are rather straightforward to compute is that a given consumer's dynamic-programming problem is mostly independent of how other consumers behave; the only relevant input is a very low-dimensional object such as an interest rate and a wage rate (which, of course, are affected by all consumers). ${ }^{11}$ Not all steady-state models with heterogeneous agents have this pleasant feature, however. One case in point is models where consumers care directly about the whole distribution of the other consumers' state variables, such as in a decentralized search-matching context (whether in a monetary, labor, or other application). A concrete example here is the setup considered in Krusell, Mukoyama, and Şahin (2010): they solve a model that is a straight marriage between Aiyagari (1994) and Pissarides (1985). In their model, a consumer's asset holdings will influence the value of being unemployed and hence, in a

\footnotetext{
${ }^{10}$ The focus of our paper is household heterogeneity, but the methodological challenges posed by models with firms heterogeneity, see, e.g., Khan and Thomas (2008) for a representative contribution, are very similar to those presented here. Our method is therefore applicable in that class of models as well.

${ }^{11}$ Moreover, for a constant-returns production function, the interest rate and the wage rate are in a oneto-one relation to each other so really only one endogenous equilibrium variable is used in the consumer's problem.
} 
bargaining situation with a firm, determine the wage outcome: a higher asset level allows you to bargain for a higher wage. Moreover, the wage as a function of asset holdings then becomes an equilibrium object that consumers need to know when solving their savings problems, since a higher rate of saving today then implies higher wages in the future according to the equilibrium wage function. Thus, the set of equilibrium variables appearing as an input into the consumer's problem is not small in this case: it is a whole function. Thus, one needs more sophisticated numerical methods to solve for this kind of stationary equilibrium.

Equilibria with heterogeneous agents and aggregate shocks were initially computationally intractable. The reason is that in such models, the recursive objects $G$ and $H$ that generalize the representative-agent framework are both infinite-dimensional. The key reason for this, in turn, is that the economy's endogenous state vector is infinite-dimensional: it consists of the whole distribution of wealth (jointly with idiosyncratic shock outcomes). The incomplete-markets assumption, namely, makes any aggregation theorem invalid as a rule, even with preferences in a suitable class and, hence, the whole distribution of asset holdings today is necessary for predicting the total amount of capital tomorrow. The reason, of course, is that agents with different amounts of wealth have different marginal propensities to consume. Denoting the distribution by $\Gamma$, we would thus have (again with a focus on output as the endogenous variable), $y=G(\Gamma, z)$ and $\Gamma^{\prime}=H(\Gamma, z)$. Linearization did not seem like a natural path forward because (i) the individual's problem (which is also a determinant of $G$ and $H$ ) is fundamentally nonlinear and (ii) linearization in infinite dimensions is a challenge ( $G$ and $H$ both have an infinite-dimensional argument and $H$ is an infinite vector-valued function).

Surprisingly, however, Krusell and Smith (1998), followed by Krusell and Smith (1997), Den Haan (1997), and Ríos-Rull (2001), found that a (fully non-linear) solution method appeared to work quite well for a set of economies that could be viewed as straightforward extensions of Huggett (1993) and Aiyagari (1994) to the case of aggregate uncertainty, or to Kydland and Prescott (1982) by adding heterogeneous agents and uninsurable id- 
iosyncratic risk. ${ }^{12}$ The approach pursued by Krusell and Smith was to summarize the distribution $\Gamma$ by a small set of moments and replace $H$ with a function that only maps this small set of moments from the current to the next period. Thus, so long as a consumer only needed to know prices which are determined by the small set of moments and these moments could be predicted well by their own past, one obtained a "solvable" setting; for a very detailed discussion of the method and a discussion of its accuracy, see Krusell and Smith (2006). It turned out, in particular, that "approximate aggregation" obtained, namely that only one moment of $\Gamma$ (the mean) sufficed for producing remarkably good forecasting accuracy.

Like in the early days of numerical representative-agent analysis, a volume appeared, now in the Journal of Economic Dynamics and Control: the issue edited by Den Haan, Judd, and Juillard (2010); a front page is displayed in the figure below. ${ }^{13}$

\footnotetext{
${ }^{12}$ Krusell and Smith (1998) also considered valued leisure; Den Haan (1997) looked at an endowment economy; and Krusell and Smith (1997) looked at portfolio choice and asset pricing.

${ }^{13}$ It proved impossible to find a front page on the internet; we would be very grateful if anyone could send us a copy of it. With a little help from a friend, Filip Rozsypal, we got by: he very kindly produced a photo-shop "replica".
} 


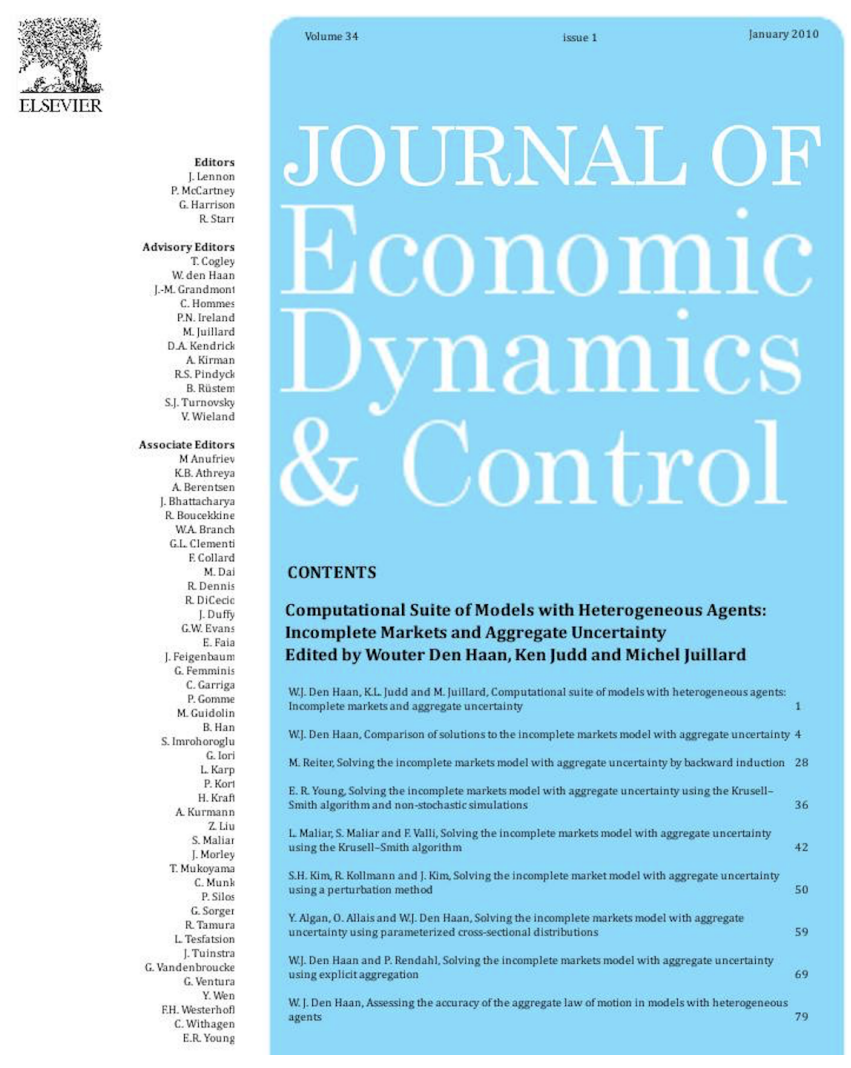

The overarching question in this JEDC issue was whether the proposed small-set-ofmoments approach was accurate enough. Hence, the issue contained papers offering a plethora of other methods and a summary of the findings in the issue was that, at least for the model under study, all the methods delivered close-to-identical equilibria and, by implication, that the small-set-of-moments approach was quite accurate and powerful.

A name in the $J E D C$ issue stands out: Michael Reiter. Reiter's earlier work (Reiter, 2009), namely, had unveiled how linearization could be accomplished in this class of models, again something that had appeared impossible. The idea here was to solve the consumer's problem at steady state fully non-linearly and then to summarize the decision rules of this problem with a finite set of parameters. These parameters were then made to depend on an aggregate state variable $\hat{\Gamma}$, which in turn was a reduced-dimension version of the full distribution $\Gamma$ (but not necessarily the moments of $\Gamma$ ). The equilibrium could then be linearized with respect to this finite vector summarizing $\Gamma$ : $G$ and $H$ can be replaced 
by (large but finite) vectors. The description of Reiter's approach here is too brief to be clear, but the point is that a sophisticated method can be designed and implemented, thus in the end allowing a feasible linearization approach also to heterogeneous-agent models with aggregate risk. Reiter (2010) offers a refined, more efficient version of the same method. Several other authors had previously explored linearization but failed to deliver a completed and tested algorithm. Since Reiter's work, more papers have offered additional linearization methods. Most recently, Ahn et al. (2017) propose a method that is particularly powerful in reducing the dimensionality efficiently. ${ }^{14}$

Substantively, Reiter's method suggested that the class of models not only appeared to satisfy approximate aggregation but also that these models were well approximated by a linear system. Interestingly, in parallel, some papers in the literature did provide fully nonlinearly obtained numerical solutions to transition paths following MIT shocks. ${ }^{15}$ I.e., they provided impulse responses. The point we make in the present paper is that under the assumption that linearization works well —as suggested by Reiter — these impulse-response functions, obtained by non-linear methods, can be used directly to also simulate the behavior of the economy under aggregate uncertainty, as outlined in the introduction and described in more detail below. The fundamental reason is that in linear systems, effects of recurring, or different, shocks are additive and the effects scalable. The assumption "linearization works well" then simply means that an impulse response, if it is a response to a small MIT shock, can be interpreted directly as a linear response. The word "small" is important here, as one should view it as of the size required to produce a numerical derivative: the entire impulse response (of all endogenous variables) should thus be viewed as a numerically computed derivative of the initial shock.

As pointed out, the methods proposed here rely on assuming that linearization works, but in this sense the approach is not different than that in most of the applied Dynarebased literature on representative agents, or that in the recent papers like Ahn et al. (2017) on solving heterogeneous-agent models: they all assume that linearization works. We do

\footnotetext{
${ }^{14} \mathrm{Ahn}$ et al. (2017) are also producing easy-to-use Dynare-like packages based on their methods.

${ }^{15}$ One example is provided in Krusell, Mukoyama, Şahin, and Smith (2009), where there is an unexpected removal of all TFP fluctuations - these shocks are replaced with their conditional mean as of time 0 - and a deterministic path toward a steady state is solved for.
} 
discuss this key assumption and propose some tests that can be conducted, namely to try out different MIT shocks (or combinations thereof) and see whether the additivity and scalability are approximately satisfied. In our example economies, these tests are passed with flying colors.

\section{The settings}

We consider a variety of models, the focus of course being on heterogeneous-agent economies. However, we also study a very standard representative-agent model to illustrate how our methods work. The representative-agent model can be solved non-linearly for a response to an MIT shock with standard Dynare commands. We then use this response to generate a simulation with shocks and use it to compute conditional moments. Therefore, we begin with a description of the representative-agent economy, after which we describe the heterogeneous-agent economy. At the end we also look at a model with a demand externality; we describe this setting last.

\subsection{A benchmark representative-agent model}

Though our benchmark representative-agent framework involves no frictions, so that one could focus on a planning problem, we describe the decentralized equilibrium here as it is the core on which the equilibrium with heterogeneous agents is later built.

The production technology is standard and involves two shocks. There is a representative firm producing under perfect competition according to the following production function:

$$
y_{t}=z_{t} k_{t}^{\alpha} h_{t}^{1-\alpha} .
$$

Thus, the firm solves

$$
\max _{k, h}=z_{t} k^{\alpha} h^{1-\alpha}-r_{t} k-w_{t} h,
$$

at time $t$ where the rental rate, $r_{t}$, and the wage rate, $w_{t}$, are taken by the firm as given. The term $z_{t}$ is a random variable that is taken by the firm as given too; it is exogenous 
and follows a stochastic process given by $\log z_{t+1}=\rho_{z} \log z_{t}+\sigma_{\epsilon_{z}} \epsilon_{z, t+1}$, with $\rho_{z} \in(0,1)$ and $\epsilon_{z}$ a standard normal shock.

Capital accumulation occurs according to

$$
k_{t+1}=(1-\delta) k_{t}+i_{t}
$$

where $i_{t}$ is investment measured in efficiency units of capital.

The resource constraint reads

$$
c_{t}+q_{t} i_{t}=y_{t},
$$

where $q_{t}$ is an investment-specific technology shock; a fall in its value increases the capacity for producing capital. We assume that the investment-specific technology too follows an $\operatorname{AR}(1)$ process in $\operatorname{logs}: \log q_{t+1}=\rho_{q} \log q_{t}+\sigma_{\epsilon_{q}} \epsilon_{q, t+1}$, with $\rho_{q} \in(0,1)$ and $\epsilon_{q}$ a standard normal shock.

There is a representative household solving

$$
\max _{\left\{k_{t+1}, b_{t+1}, h_{t}, c_{t}\right\}_{t=0}^{\infty}} E_{0}\left\{\sum_{t=0}^{\infty} \beta^{t} u\left(c_{t}, h_{t}\right)\right\},
$$

subject to

$$
q_{t} k_{t+1}+b_{t+1}=\left(q_{t}(1-\delta)+r_{t}\right) k_{t}+b_{t}\left(1+\tilde{r}_{t}\right)+w_{t} h_{t}-c_{t}-T_{t},
$$

$h_{t}, c_{t} \geq 0$, and a standard no-Ponzi scheme condition. We have $0<\beta<1, \sigma>0$, and $\theta>0$. Labor supply is endogenous; $T$ is a lump-sum transfer that will be considered only in the heterogeneous-agent model. We note that there are two assets: physical capital and government bonds (denoted by $b$ ). They must have the same return in a deterministic version of the model and, under aggregate uncertainty and a linearized equilibrium, the same expected return, even though government bonds gives a safe return and the return to capital is risky:

$$
1+\tilde{r}_{t+1}=E_{t}\left[\frac{q_{t+1}}{q_{t}}(1-\delta)+\frac{r_{t+1}}{q_{t}}\right] .
$$


The government budget, finally, reads

$$
b_{t+1}=b_{t}\left(1+\tilde{r}_{t}\right)-T_{t} .
$$

When we implement a budget rule in the heterogeneous-agent model we will be more specific on the joint path $T$ and $b$; in the representative-agent model Ricardian Equivalence holds so whatever rule is in place will not affect the equilibrium allocation.

The equilibrium characterization is straightforward and standard. The first-order conditions of the household problem read

$$
u_{c}\left(c_{t}, h_{t}\right)=\beta E_{t}\left\{\left(\frac{q_{t+1}}{q_{t}}(1-\delta)+\frac{r_{t+1}}{q_{t}}\right) u_{c}\left(c_{t+1}, h_{t+1}\right),\right\}
$$

and

$$
u_{c}\left(c_{t}, h_{t}\right) w_{t}=-u_{h}\left(c_{t}, h_{t}\right) \text {, }
$$

together with a transversality condition. The firm's first-order conditions are

$$
r_{t}=\alpha z_{t}\left(k_{t} / h_{t}\right)^{-(1-\alpha)},
$$

and

$$
w_{t}=(1-\alpha) z_{t}\left(k_{t} / h_{t}\right)^{\alpha} .
$$

The equilibrium sequence $\left\{c_{t}, h_{t}, k_{t+1}\right\}_{t=0}^{\infty}$ is then simply given by

$$
\begin{gathered}
u_{c}\left(c_{t}, h_{t}\right)=\beta E_{t}\left\{\left[\frac{q_{t+1}}{q_{t}}(1-\delta)+\frac{\alpha z_{t+1}}{q_{t}}\left(k_{t+1} / h_{t+1}\right)^{-(1-\alpha)}\right] u_{c}\left(c_{t+1}, h_{t+1}\right)\right\}, \\
u_{c}\left(c_{t}, h_{t}\right)(1-\alpha) z_{t}\left(k_{t} / h_{t}\right)^{\alpha}=-u_{h}\left(c_{t}, h_{t}\right),
\end{gathered}
$$

and

$$
q_{t} k_{t+1}=(1-\delta) q_{t} k_{t}+z_{t} k_{t}^{\alpha} h_{t}^{1-\alpha}-c_{t}
$$

which amounts to a system of stochastic difference equations in the sequences for consumption, hours, and capital, with the restrictions $k_{0}$ and a limit condition that combines the 
no-Ponzi game constraint and a transversality condition; the stochastic $z$ and $q$ processes are an exogenously given determinant of the consumption, hours, and capital processes.

The steady state can be found as a solution $(k, h, c)$ to the above equations when shocks are constant (and normalized to 1), i.e., three equations in three unknowns:

$$
\begin{gathered}
1=\beta\left(1-\delta+\alpha(k / h)^{-(1-\alpha)}\right), \\
u_{c}(c, h)(1-\alpha)(k / h)^{\alpha}=-u_{h}(c, h),
\end{gathered}
$$

and

$$
\delta k=k^{\alpha} h^{1-\alpha}-c .
$$

In our application we will use the following functional form of preferences:

$$
u\left(c_{t}, h_{t}\right)=\frac{c_{t}^{1-\sigma}-1}{1-\sigma}-\psi \frac{h_{t}^{1+\frac{1}{\theta}}}{1+\frac{1}{\theta}}
$$

\section{$3.2 \quad$ The heterogeneous-agent model}

We now describe the model when consumers are subject to idiosyncratic shocks. For easier notation, we describe it without transfers and bonds but our computations include the same kinds of taxes as used in the representative-agent setting.

In the heterogeneous-agent model, different consumers will have different amounts of efficiency units of labor per hour worked and different levels of wealth. Wages thus consist of two components: an aggregate part, $w$, and an idiosyncratic one, $\epsilon$, which is independent across consumers and for which a law of large number holds. There is no direct insurance against wage shocks but workers can save and they can borrow subject to a borrowing constraint: their borrowing must not exceed $-\underline{k}$. The implication of these assumptions is that a workers wealth will fluctuate over time - reflecting precautionary savings - and that the marginal propensities to consume and work will vary in the population. Hence, changes in the aggregate economy, e.g., through policy, will generate nontrivial responses by the aggregate of consumers. Hence, the joint distribution of $\epsilon$ and wealth will matter 
for outcomes in this model; we will denote this distribution $\Gamma$ and it will be defined below. This distribution is also the high-dimensional state variable that makes computation in this class of models challenging as it will evolve endogenously over time. In a steady state it will be constant: individual wealth and income will vary stochastically but the overall distribution of these quantities across individuals will not change.

Aside from aggregate prices today and in the future, the consumers decision will be informed by the initial individual state, which can be summarized here by the idiosyncratic wage shock, $\epsilon$, and cash on hand (excluding current labor income), which we denote $\omega$. We formulate the consumer's problem recursively and we begin by defining a stationary equilibrium. For all $(\omega, \epsilon)$, the following functional equation has to be met:

$$
V(\omega, \epsilon)=\max _{k^{\prime}, h} u\left(\omega+\epsilon w h-k^{\prime}, h\right)+\beta E\left[V\left(k^{\prime}(1-\delta+r), \epsilon^{\prime}\right) \mid \epsilon\right]
$$

s.t. $k^{\prime} \geq \underline{k}$. Here, $\epsilon$ is some (idiosyncratic) productivity process on finite support to be specified later. This problem leads to a pair of decision rules for capital accumulation and hours: $f_{k}(\omega, \epsilon)$ and $f_{h}(\omega, \epsilon)$, respectively.

A stationary equilibrium can now be defined as prices $r$ and $w$, decision rules $f_{k}$ and $f_{h}$, and a stationary distribution $\Gamma$ such that

1. $f_{k}(\omega, \epsilon)$ and $f_{h}(\omega, \epsilon)$ attain the maximum in the consumer's problem for all $(\omega, \epsilon)$;

2. $r=F_{k}(\bar{k}, \bar{h})$ and $w=F_{h}(\bar{k}, \bar{h})$, where $\bar{k} \equiv\left(\sum_{\epsilon} \int_{\omega} \omega \Gamma(d \omega, \epsilon)\right) /(1-\delta+r)$ and $\bar{h} \equiv$ $\sum_{\epsilon} \int_{\omega} \epsilon f_{h}(\omega, \epsilon) \Gamma(d \omega, \epsilon) ;$ and

3. for all relevant Borel sets $B, \Gamma(B, \epsilon)=\sum_{\tilde{\epsilon}} \pi_{\epsilon \mid \tilde{\epsilon}} \int_{\omega: f_{k}(\omega, \tilde{\epsilon})(1-\delta+r) \in B} \Gamma(d \omega, \tilde{\epsilon})$.

In this definition we use $F(k, h) \equiv k^{\alpha} h^{1-\alpha}$ and we implicitly, then, set $z=1$; similarly, we implicitly set $q=1$.

An equilibrium with aggregate shocks can be defined as well in a standard manner. We instead define the equilibrium we will compute, that is, a deterministic equilibrium where $z$ and $q$ follow predictable paths. ${ }^{16}$ In an equilibrium, we have a consumer's problem that

\footnotetext{
${ }^{16}$ Our definition here also serves the role of highlighting how the agent's problem in a transition-path equilibrium is very similar to that in a steady state and, hence, can be computed in a very similar way.
} 
can be written, for all $t$,

$$
V_{t}(\omega, \epsilon)=\max _{k^{\prime} \geq \underline{k}, h} u\left(\omega+\epsilon w_{t} h-k^{\prime}, h\right)+\beta E\left[V_{t+1}\left(k^{\prime}\left(\frac{q_{t+1}}{q_{t}}(1-\delta)+\frac{r_{t+1}}{q_{t}}\right), \epsilon^{\prime}\right) \mid \epsilon\right] .
$$

This problem leads to decision rules $f_{k, t}(\omega, \epsilon)$ and $f_{h, t}(\omega, \epsilon)$.

A sequential equilibrium can now be defined as the sequences of prices $\left\{r_{t}\right\}_{t=0}^{\infty}$ and $\left\{w_{t}\right\}_{t=0}^{\infty}$, decision rules $\left\{f_{k, t}\right\}_{t=0}^{\infty}$ and $\left\{f_{h, t}\right\}_{t=0}^{\infty}$, and a distribution $\left\{\Gamma_{t}\right\}_{t=0}^{\infty}$ such that

1. $f_{k, t}(\omega, \epsilon)$ and $f_{h, t}(\omega, \epsilon)$ attain the maximum in the consumer's problem for all $(\omega, \epsilon)$ and $t$;

2. $r_{t}=z_{t} F_{k}\left(\bar{k}_{t}, \bar{h}_{t}\right)$ and $w_{t}=z_{t} F_{h}\left(\bar{k}_{t}, \bar{h}_{t}\right)$, where $\bar{k}_{t} \equiv\left(\sum_{\epsilon} \int_{\omega} \omega \Gamma_{t}(d \omega, \epsilon)\right) /\left(\frac{q_{t+1}}{q_{t}}(1-\delta)+\frac{r_{t+1}}{q_{t}}\right)$ and $\bar{h}_{t} \equiv \sum_{\epsilon} \int_{\omega} \epsilon f_{h, t}(\omega, \epsilon) \Gamma_{t}(d \omega, \epsilon) ;$ and

3. for all relevant Borel sets $B, \Gamma_{t+1}(B, \epsilon)=\sum_{\tilde{\epsilon}} \pi_{\epsilon \mid \tilde{\epsilon}} \int_{\omega: f_{k, t}(\omega, \tilde{\epsilon})\left(\frac{q_{t+1}}{q_{t}}(1-\delta)+\frac{r_{t+1}}{q_{t}}\right) \in B} \Gamma_{t}(d \omega, \tilde{\epsilon})$.

\subsection{Adding a demand externality}

We now look at a simple extension whose main purpose is computational: to try to solve for an equilibrium where two aggregate (price or quantity) sequences need to be guessed and iterated upon in order to solve for a transitional equilibrium in response to an MIT shock away from steady state.

Thus, assume that the aggregate production function reads

$$
y_{t}=A_{t} k_{t}^{\alpha} h_{t}^{1-\alpha}
$$

where $A_{t} \equiv z_{t} \phi\left(c_{t}\right)$ is taken as given by firms but $c_{t}$ denotes aggregate consumption. The factor $\phi\left(c_{t}\right)$ thus captures the externality; it is an increasing function and can perhaps be thought of as a "utilization" function driven by consumption demand.

Thus, the firm solves

$$
\max _{k, h}=A_{t} k^{\alpha} h^{1-\alpha}-r_{t} k-w_{t} h
$$

at time $t$. 
Given this formulation, one can ask how a planner would wish to choose an allocationin what way the market allocation fails. However, that is not our aim here. Rather, let us note that if $c_{t}$ does not appear as an argument in TFP, i.e., if there is no consumption externality, then knowing the capital-labor ratio, along with $z_{t}$, one can compute the equilibrium prices $r_{t}$ and $w_{t}$. With an externality, however, the capital-labor ratio is not sufficient information: one needs to know both this ratio and the level of consumption. Therefore, when solving for a transition equilibrium in response to an MIT shock, one needs to guess on two sequences (either for $r$ and $w$ or for $c$ and $k / h$ ) in order to have enough information so that the consumer's problem is fully specified and can be solved. This is not a model virtue per se, of course; we merely add a "complication" so that we can put our method to a slightly more demanding test.

\section{Numerical approach}

Here we describe some details of our computations.

Representative-agent model We solve the representative-agent model in Dynare. Dynare has a routine that solves for a transition path nonlinearly, and we use this routine to find the transitional equilibrium. We start at a steady state and consider a small increase in $z_{0}$ and a subsequent deterministic transition of $z_{1}, z_{2}$, and so on, back toward 1 . We treat the resulting transitional path for output (and any other aggregates of interest) as an impulse response - a numerical derivative of output $k$ periods hence in response to a shock to (the logarithm of) $z$ at time 0 - and then use this impulse response in simulations to obtain realizations of the stochastic equilibrium based on which we then compute unconditional moments. We then compute another transition path, this time for an innovation to (the logarithm of) $q$, and compute the deterministic transition path. These paths are then employed to run simulations and compute unconditional moments - in the case of output only, its autocorrelation function - that can be compared to those produced by the standard Dynare output based on linearization.

In carrying out these computations and comparisons, accuracy is improved by (i) 
choosing an appropriately small initial shock (so as to approximate a numerical derivative as well as possible); (ii) setting a small enough tolerance level for Dynare's nonlinear routine; and (iii) allowing sufficiently many time periods in the impulse response.

Heterogeneous-agent model, stationary equilibrium For the heterogeneous-agent model the first step is to find a stationary equilibrium. We carry this task out using our own MATLAB code. The consumer's problem is solved on a grid using the endogenous grid point method of Carroll (2006). ${ }^{17}$ The individual income process is an AR(1) process and we use 7 grid points to discretize the process into a Markov chain using Rouwenhorst's method (Kopecky and Suen, 2010). For the decision rules, the asset grid has 50 points, non-linearly spaced, and households can choose points off the grid by piecewise cubic interpolation (pchip in MATLAB). The dynamic programming problem is then solved by evaluating the value function at the optimal decisions for consumption, hours, and savings.

The steady state is solved for simultaneously with the calibration of the capital-output ratio and hours worked. Instead of having nested loops - where one guesses on parameters, then conditional on those parameters solves for market clearing prices, then checks if those prices are consistent with the calibration targets - there is only one loop where we use parameters to clear markets at fixed prices (instead of using prices to clear markets at fixed parameters). The target for the capital-output ratio (10.26, quarterly) pins down the real rate and wages, and the target for hours (1/3) pins down the level of aggregate capital. To find the steady state given these prices and quantities, one guesses on $\beta$ and $\psi$, solves the household problem and computes aggregate assets and labor supplied by the households. If either quantity is too high or too low relative to the demand from firms, the guesses are updated. We use a MATLAB's fsolve solver, which employs a trust-region method to solve for the values of $\beta=0.985$ and $\psi=8.024$ that clear the markets. The stationary distribution is solved for by approximating the distribution using

\footnotetext{
${ }^{17}$ The method involves guessing a policy rule for consumption of a function of assets and idiosyncratic productivity, setting a grid on tomorrow's assets, then solving (in closed form) for today's consumption using the Euler equation of the household. This then allows one to cover the implied grid for today's assets consistent (hence giving the method its name) which is then used to update the consumption function. We do the updating by interpolating the consumption function between the exogenous and endogenous grids using piecewise cubic interpolation.
} 
a histogram over income and assets defined on a finer grid than the policy functions - 1,000 points (also non-linearly spaced). We compute the transition matrix between individual states using the policy functions of households and the Markov transition matrix for labor productivity. We recover the invariant distribution by finding the eigenvector associated with the largest eigenvalue (1) of the transition matrix. Aggregate savings and labor supply is then straightforwardly computed as the sum of savings over the invariant distribution.

Heterogeneous-agent model, transitional equilibrium To solve for a transitional equilibrium we also use a home-made MATLAB code. The solution algorithm here is outlined as follows:

\section{Transitional Equilibrium Algorithm}

1. Choose a time $T$ at which point we assume the economy has reached steady state.

2. Guess a path for the capital-labor ratio, $\left(\left\{K_{t} / H_{t}\right\}_{t=0}^{T}\right)^{0}$.

3. Solve the value function (and policy functions) backwards from $t=T-1, \ldots 1$ setting $V^{T}=V^{S S}$

4. Starting from the steady state distribution, simulate the distribution forward from $t=1, \ldots, T$ using the policy functions and idiosyncratic productivity Markov transition matrix.

5. At each $t$, compute aggregate capital and labor supplied $K_{t}^{S}, H_{t}^{S}$ using the distribution and policy functions.

6. Compute the maximum difference between supply and demand $\zeta=\max \mid K_{t} / H_{t}-$ $K_{t}^{S} / H_{t}^{S} \mid$.

7. If $\zeta<10^{-5} \min \left\{\epsilon_{x, 0}, 1\right\}$, STOP.

8. Update guess ${ }^{18}\left(\left\{K_{t} / H_{t}\right\}_{t=0}^{T}\right)^{1}=v\left(\left\{K_{t} / H_{t}\right\}_{t=0}^{T}\right)^{0}+(1-v)\left\{K_{t}^{S} / H_{t}^{S}\right\}_{t=0}^{T}$ and GO TO 2.

\footnotetext{
${ }^{18}$ The particular values we choose for $v$ are 0.8 , when the deviation $\zeta$ is greater than $10^{-4}$, and 0.65 otherwise.
} 
The basic idea is that after some long amount of time (here $T=350$ quarters) the economy will return to the original steady state. Thus, we are guessing on a transition path back to the original steady state. In order to solve the households' and firms' problems we need to know the path of prices along the transition. The capital-labor ratio is sufficient to pin down the prices, thus, by guessing a path for the capital-labor ratio we have all the prices that we need. ${ }^{19}$ Thus, then we can take the original steady state value function as our terminal condition and solve the household problem backwards. We then simulate the distribution over households forward starting with the steady state distribution. If the path of the capital output ratio implied by the policy functions and distribution is sufficiently close to our guess, we've solved for the equilibrium and we're done. Otherwise, we update the guess by taking a convex combination between the guessed path and the path implied by simulating forward. Despite the fact that the shooting method that we use for the transition path does not have well established convergence properties, in practice we find that our algorithm achieves roughly first-order convergence when beginning with an initial guess for the path of the capital-labor ratio obtained from the representativeagent model. Thus, typically we can achieve our desired level of convergence in less than 15 iterations.

The simulation of a stochastic equilibrium is identical to that used for the representativeagent model.

\section{$5 \quad$ Parameter selection}

\subsection{Calibration}

Our calibration is straightforward. For the standard parameters we use $\alpha=0.36$ to match the capital share, $\delta=0.025$ to match a real rate of $4 \%$ per year, and $\sigma=1$ (logarithmic curvature) as a benchmark value used in the literature. We choose a Frisch elasticity $\theta$ of 1 , again as a standard in the literature. We use standard parameters for the technology shocks, a serial correlation coefficient $\rho_{z}$ for TFP of 0.95 , and a $\rho_{q}$ for the

\footnotetext{
${ }^{19}$ We typically use the solution to the representative-agent model as the initial guess for solving the transition.
} 
investment-specific shock of 0.9 , with standard deviations $\sigma_{z}$ for TFP of 0.007 and $\sigma_{q}$ for the investment-specific shock of 0.02 .

We calibrate the income process following Krueger, Mitman, and Perri (2016) who estimate a process for disposable earnings after taxes and transfers using the PSID. They estimate the quarterly persistence for innovations, $\rho_{y}$, to be 0.9923 and the standard deviation, $\sigma_{y}$, to be 0.0983 . We treat their measured transitory shock as measurement error.

\subsection{Findings}

We begin with the representative-agent (RA) economy, where we can implement our method using only Dynare's model solution. We then display results for the benchmark heterogeneous-agent (HA) model, after which we produce checks on the linearity assumption. We finally present results from the model with an externality and with policy.

\subsubsection{The RA case}

Figure 1 displays the impulse response function for output and various aggregates for the RA economy. These results are computed using Dynare's nonlinear transition algorithm. Unless otherwise noted, we always select innovations of size $\epsilon_{x, 0}=0.01$.

The figure reports impulse responses that have the expected shape and, by ocular inspection, look just like those obtained from Dynare's standard, linearization-based impulse response command (we omit showing the latter for brevity). What is key here, however, is that we can now simulate the representative-agent economy with aggregate shocks based on these impulse responses and compare its features to those generated by Dynare's linearization-based algorithm, as well as for its higher orders of perturbation. These results are contained in Table 1 below. Our method produces nearly identical correlation statistics to those using Dynare linearization and they are also very close to the values using second-order perturbation.

For the benchmark simulation method we used 500 periods from the deterministic impulse response functions. It is instructive to understand how the approximation varies 

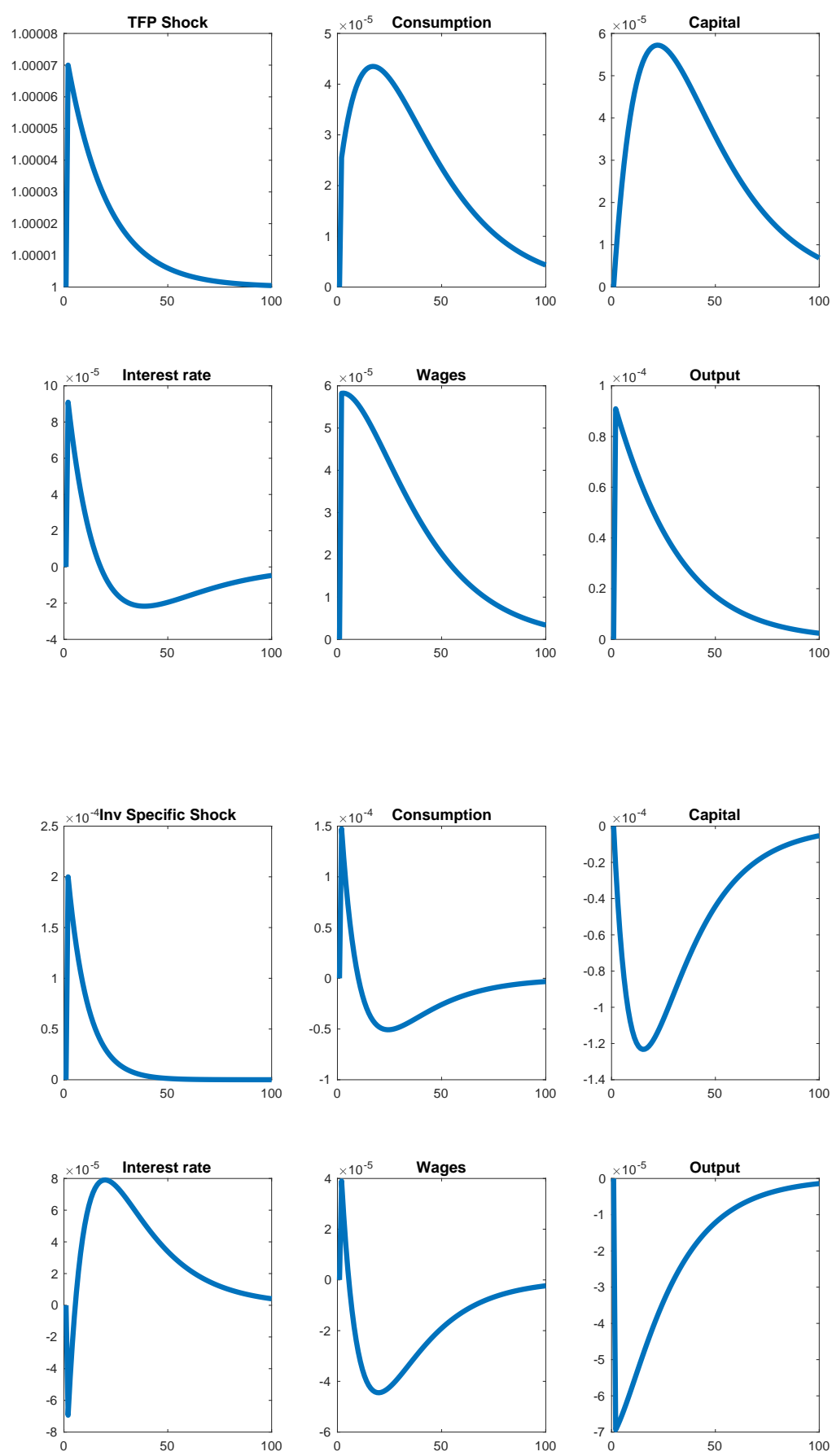

Figure 1: Impulse responses to neutral (top) and investment-specific (bottom) technology shocks for the representative-agent economy 
Table 1: Correlations between variables — RA economy

\begin{tabular}{|c|c|c|c|c|c|c|c|}
\hline$z$ & $q$ & $y$ & $c$ & $i$ & $h$ & $r$ & $w$ \\
\hline \multicolumn{8}{|c|}{ Our method $(N=500)$} \\
\hline 1.000 & -0.021 & 0.785 & 0.506 & 0.286 & 0.372 & 0.199 & 0.748 \\
\hline-0.021 & 1.000 & -0.533 & 0.324 & -0.856 & -0.911 & 0.156 & -0.124 \\
\hline 0.785 & -0.533 & 1.000 & 0.496 & 0.512 & 0.686 & -0.257 & 0.867 \\
\hline 0.506 & 0.324 & 0.496 & 1.000 & -0.492 & -0.284 & -0.614 & 0.863 \\
\hline 0.286 & -0.856 & 0.512 & -0.492 & 1.000 & 0.969 & 0.349 & 0.016 \\
\hline 0.372 & -0.911 & 0.686 & -0.284 & 0.969 & 1.000 & 0.137 & 0.236 \\
\hline 0.199 & 0.156 & -0.257 & -0.614 & 0.349 & 0.137 & 1.000 & -0.502 \\
\hline 0.748 & -0.124 & 0.867 & 0.863 & 0.016 & 0.236 & -0.502 & 1.000 \\
\hline \multicolumn{8}{|c|}{ Dynare 1st order } \\
\hline 1.000 & -0.021 & 0.785 & 0.506 & 0.286 & 0.372 & 0.199 & 0.748 \\
\hline-0.021 & 1.000 & -0.533 & 0.324 & -0.855 & -0.911 & 0.156 & -0.124 \\
\hline 0.785 & -0.533 & 1.000 & 0.496 & 0.512 & 0.686 & -0.257 & 0.867 \\
\hline 0.506 & 0.324 & 0.496 & 1.000 & -0.492 & -0.284 & -0.614 & 0.863 \\
\hline 0.286 & -0.855 & 0.512 & -0.492 & 1.000 & 0.969 & 0.349 & 0.016 \\
\hline 0.372 & -0.911 & 0.686 & -0.284 & 0.969 & 1.000 & 0.136 & 0.236 \\
\hline 0.199 & 0.156 & -0.257 & -0.614 & 0.349 & 0.136 & 1.000 & -0.502 \\
\hline 0.748 & -0.124 & 0.867 & 0.863 & 0.016 & 0.236 & -0.502 & 1.000 \\
\hline \multicolumn{8}{|c|}{ Dynare 2nd order } \\
\hline 1.000 & -0.021 & 0.784 & 0.505 & 0.287 & 0.368 & 0.200 & 0.746 \\
\hline-0.021 & 1.000 & -0.534 & 0.323 & -0.855 & -0.909 & 0.157 & -0.125 \\
\hline 0.784 & -0.534 & 1.000 & 0.496 & 0.512 & 0.681 & -0.258 & 0.867 \\
\hline 0.505 & 0.323 & 0.496 & 1.000 & -0.492 & -0.287 & -0.615 & 0.863 \\
\hline 0.287 & -0.855 & 0.512 & -0.492 & 1.000 & 0.967 & 0.350 & 0.016 \\
\hline 0.368 & -0.909 & 0.681 & -0.287 & 0.967 & 1.000 & 0.137 & 0.232 \\
\hline 0.200 & 0.157 & -0.258 & -0.615 & 0.350 & 0.137 & 1.000 & -0.503 \\
\hline 0.746 & -0.125 & 0.867 & 0.863 & 0.016 & 0.232 & -0.503 & 1.000 \\
\hline
\end{tabular}


with the length of the IRF used for the linearization. In Table 2 we display the model correlations when we use our method with 10, 100, and 500 (benchmark) periods of the IRF for the linearization. As the shocks are persistent, the approximations begin to differ when only using a truncated history of the shocks, suggesting that a longer time horizon is necessary for an accurate approximation when using highly persistent shocks. However, the 100-period simulation length still does a decent job under this scenario.

Table 2: Correlations between variables - RA economy

\begin{tabular}{|c|c|c|c|c|c|c|c|}
\hline$z$ & $q$ & $y$ & $c$ & $i$ & $h$ & $r$ & $w$ \\
\hline \multicolumn{8}{|c|}{ Benchmark $(N=500)$} \\
\hline 1.000 & -0.021 & 0.785 & 0.506 & 0.286 & 0.372 & 0.199 & 0.748 \\
\hline-0.021 & 1.000 & -0.533 & 0.324 & -0.856 & -0.911 & 0.156 & -0.124 \\
\hline 0.785 & -0.533 & 1.000 & 0.496 & 0.512 & 0.686 & -0.257 & 0.867 \\
\hline 0.506 & 0.324 & 0.496 & 1.000 & -0.492 & -0.284 & -0.614 & 0.863 \\
\hline 0.286 & -0.856 & 0.512 & -0.492 & 1.000 & 0.969 & 0.349 & 0.016 \\
\hline 0.372 & -0.911 & 0.686 & -0.284 & 0.969 & 1.000 & 0.137 & 0.236 \\
\hline 0.199 & 0.156 & -0.257 & -0.614 & 0.349 & 0.137 & 1.000 & -0.502 \\
\hline 0.748 & -0.124 & 0.867 & 0.863 & 0.016 & 0.236 & -0.502 & 1.000 \\
\hline \multicolumn{8}{|c|}{$N=100$} \\
\hline 1.000 & -0.018 & 0.778 & 0.503 & 0.284 & 0.369 & 0.198 & 0.741 \\
\hline-0.018 & 1.000 & -0.540 & 0.312 & -0.853 & -0.911 & 0.174 & -0.135 \\
\hline 0.778 & -0.540 & 1.000 & 0.499 & 0.512 & 0.688 & -0.271 & 0.868 \\
\hline 0.503 & 0.312 & 0.499 & 1.000 & -0.489 & -0.278 & -0.616 & 0.863 \\
\hline 0.284 & -0.853 & 0.512 & -0.489 & 1.000 & 0.968 & 0.337 & 0.018 \\
\hline 0.369 & -0.911 & 0.688 & -0.278 & 0.968 & 1.000 & 0.120 & 0.241 \\
\hline 0.198 & 0.174 & -0.271 & -0.616 & 0.337 & 0.120 & 1.000 & -0.511 \\
\hline 0.741 & -0.135 & 0.868 & 0.863 & 0.018 & 0.241 & -0.511 & 1.000 \\
\hline \multicolumn{8}{|c|}{$N=10$} \\
\hline 1.000 & 0.007 & 0.784 & 0.420 & 0.329 & 0.345 & 0.808 & 0.924 \\
\hline 0.007 & 1.000 & -0.599 & 0.819 & -0.932 & -0.934 & -0.064 & 0.051 \\
\hline 0.784 & -0.599 & 1.000 & -0.108 & 0.804 & 0.828 & 0.593 & 0.751 \\
\hline 0.420 & 0.819 & -0.108 & 1.000 & -0.678 & -0.644 & 0.050 & 0.576 \\
\hline 0.329 & -0.932 & 0.804 & -0.678 & 1.000 & 0.997 & 0.409 & 0.211 \\
\hline 0.345 & -0.934 & 0.828 & -0.644 & 0.997 & 1.000 & 0.381 & 0.253 \\
\hline 0.808 & -0.064 & 0.593 & 0.050 & 0.409 & 0.381 & 1.000 & 0.521 \\
\hline 0.924 & 0.051 & 0.751 & 0.576 & 0.211 & 0.253 & 0.521 & 1.000 \\
\hline
\end{tabular}




\subsubsection{The HA case}

Turning to the heterogeneous-agent economy, our impulse response functions for output and other aggregates are contained in Figures 2 and 3 below, where we include the IRFs from the representative-agent economy for comparison.
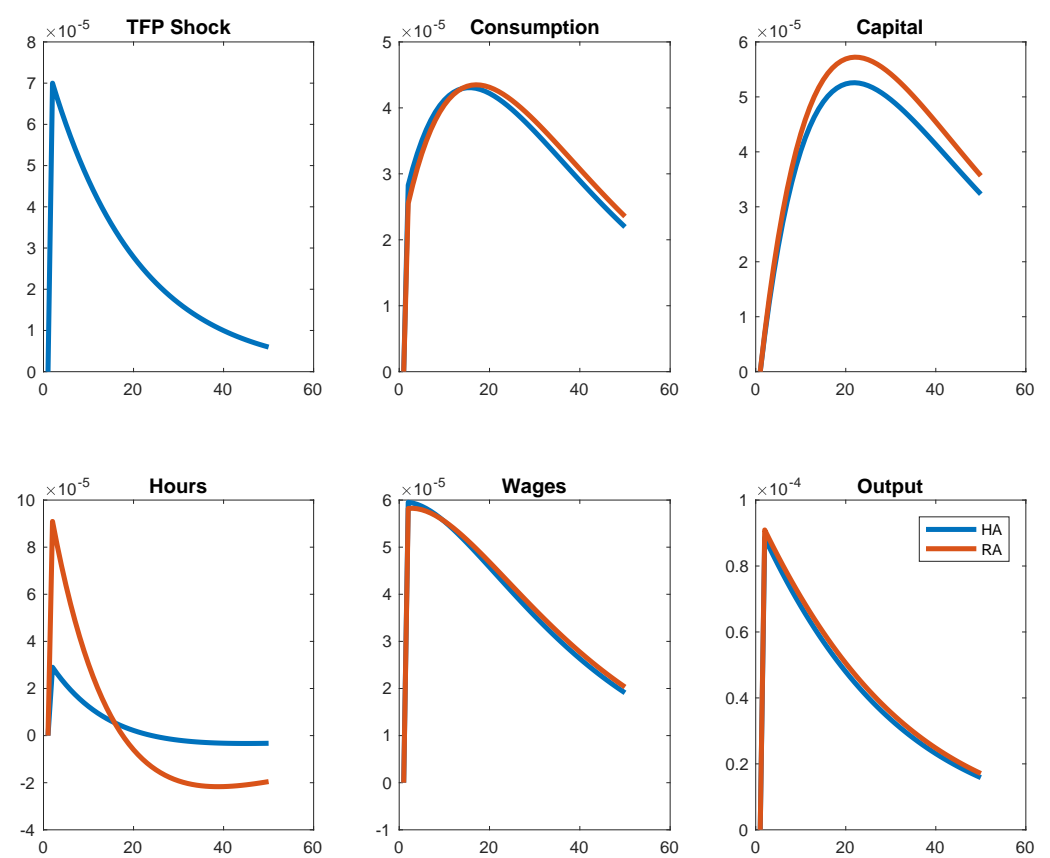

Figure 2: Impulse response to neutral technology shock for the HA and RA economies

The impulse response in the heterogeneous-agent model looks quite similar to that in the representative-agent setting in the case of a neutral technology shock, though, there is a noticeable difference in the response of hours and the capital stock. However, in response to the investment-specific shock we note significantly more propagation in the heterogeneous-agent relative to the representative-agent economy, with all series noticeably different.

Given this impulse response we then generate output for an economy with aggregate shocks based on treating the impulse response above as a linear response. We simulate 

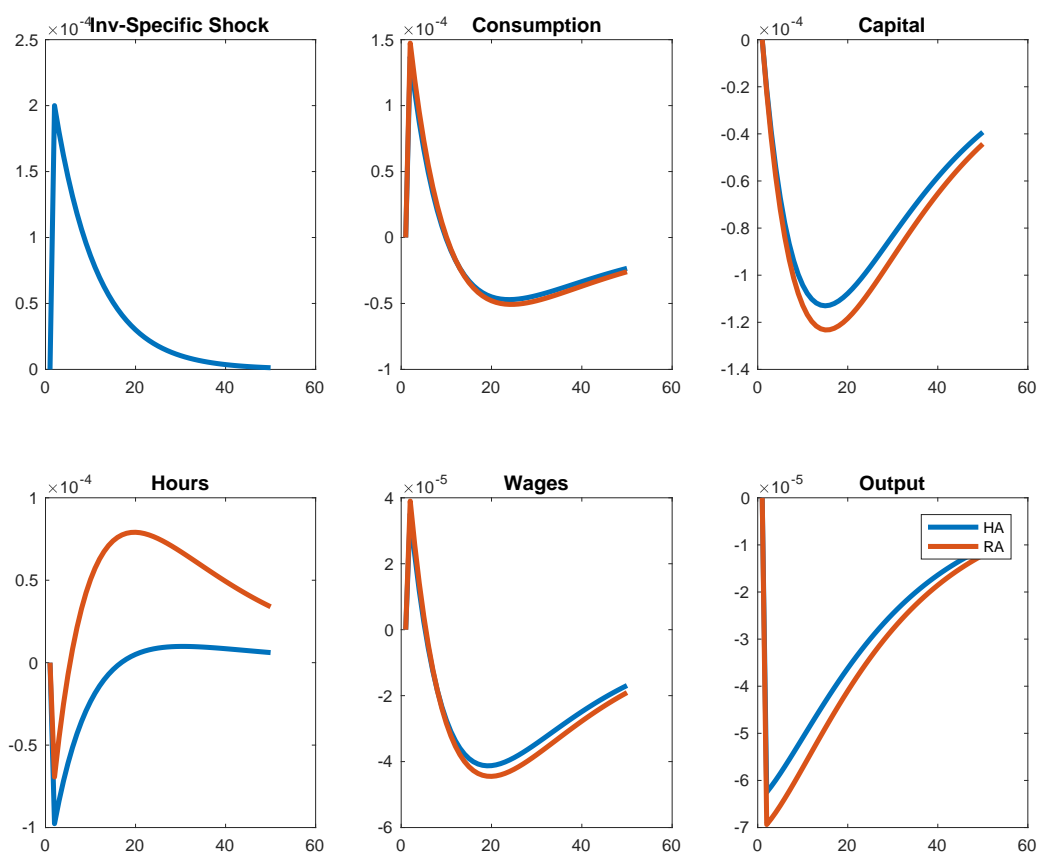

Figure 3: Impulse response to investment-specific technology shock for the HA and RA economies 
shocks for 10,500 periods and discard the first 500 periods of the simulation. One of the advantages of our approximation procedure is that we are able to directly simulate interesting statistics from the distribution. For example, in Table 3 we include the Gini coefficient of the wealth distribution and the fraction of households that are borrowing constrained (the steady-state values are 0.77 for the Gini and $26 \%$ for the constrained). We include the impulse responses for the Gini and fraction of hand-to-mouth (HtM) households in Figure 4.

Table 3: Correlations between variables - HA economy

\begin{tabular}{cccccccccc}
\hline$z$ & $q$ & $y$ & $c$ & $i$ & $h$ & $r$ & $w$ & HtM & Gini \\
\hline \hline \multicolumn{3}{c}{ HA model } \\
\hline 1.000 & -0.021 & 0.807 & 0.537 & 0.370 & 0.263 & 0.229 & 0.772 & -0.289 & -0.337 \\
-0.021 & 1.000 & -0.512 & 0.310 & -0.908 & -0.838 & 0.171 & -0.131 & 0.426 & 0.500 \\
0.807 & -0.512 & 1.000 & 0.526 & 0.671 & 0.467 & -0.212 & 0.881 & -0.709 & -0.772 \\
0.537 & 0.310 & 0.526 & 1.000 & -0.269 & -0.506 & -0.567 & 0.865 & -0.669 & -0.643 \\
0.370 & -0.908 & 0.671 & -0.269 & 1.000 & 0.958 & 0.145 & 0.247 & -0.294 & -0.386 \\
0.263 & -0.838 & 0.467 & -0.506 & 0.958 & 1.000 & 0.379 & -0.006 & -0.019 & -0.111 \\
0.229 & 0.171 & -0.212 & -0.567 & 0.145 & 0.379 & 1.000 & -0.443 & 0.805 & 0.771 \\
0.772 & -0.131 & 0.881 & 0.865 & 0.247 & -0.006 & -0.443 & 1.000 & -0.792 & -0.814 \\
-0.289 & 0.426 & -0.709 & -0.669 & -0.294 & -0.019 & 0.805 & -0.792 & 1.000 & 0.985 \\
-0.337 & 0.500 & -0.772 & -0.643 & -0.386 & -0.111 & 0.771 & -0.814 & 0.985 & 1.000 \\
\hline
\end{tabular}
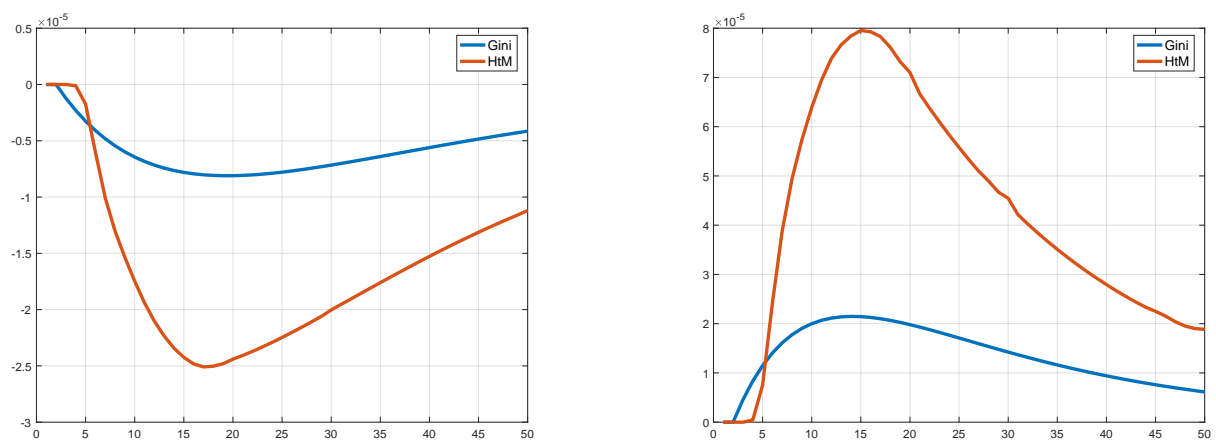

Figure 4: Distributional impulse responses to the neutral shock (left) and investmentspecific shock (right) for the HA economy 


\subsubsection{Are the responses linear? Some tests}

Next, we explore the appropriateness of the linearity and symmetry assumptions implicit in our methodology. For brevity, we limit our tests to the HA economy, but similar results obtain in the RA case. First, we compute the impulse responses for the $z$ and $q$ shocks of sizes for \pm 0.01 and \pm 2 standard deviations to investigate whether the deterministic IRFs exhibit asymmetries or non-linearities. The normalized (by shock size) impulse responses for output to productivity are plotted in Figure 5. The values are normalized by the size of the initial shock (i.e., in log deviations from steady-state consumption divided by the $\log$ of productivity, $\left.z_{0}\right)$. The solid and dotted lines correspond to the $0.01 \%$ and $-0.01 \%$ impulse responses, respectively. Note that there is a striking absence of asymmetry or non-linearity in the shocks. We plot the equivalent figure for investment-specific shocks in Figure 6 with virtually the same result, though here there is a visible deviation with a slightly smaller response for the larger positive shock.

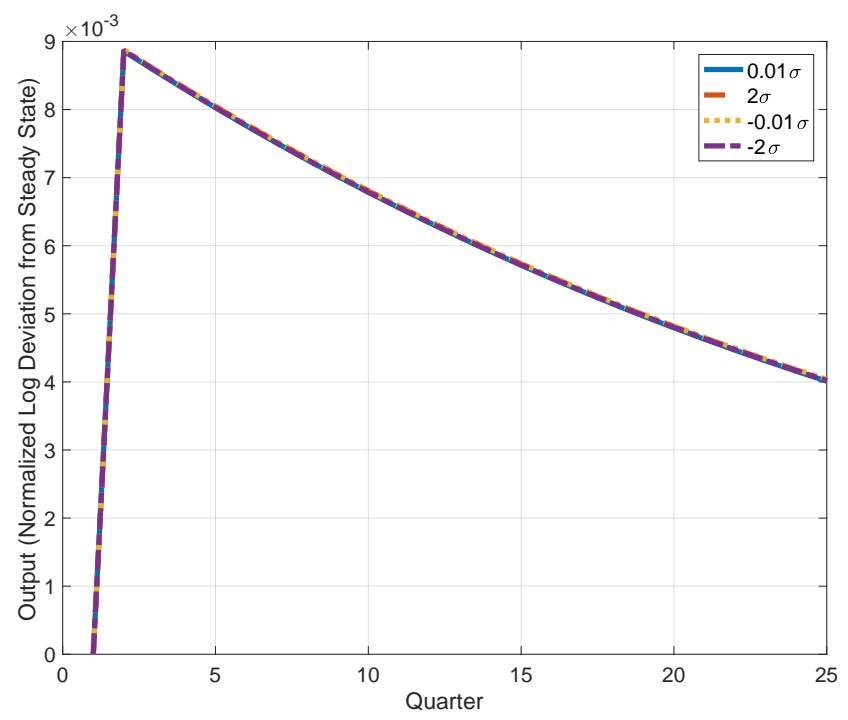

Figure 5: Normalized impulse responses for small/large positive/negative neutral shocks

Next, we assess the appropriateness of linearity in the number of shocks. We compute the perfect-foresight impulse responses for both $z$ and $q$ shocks occurring at the same 


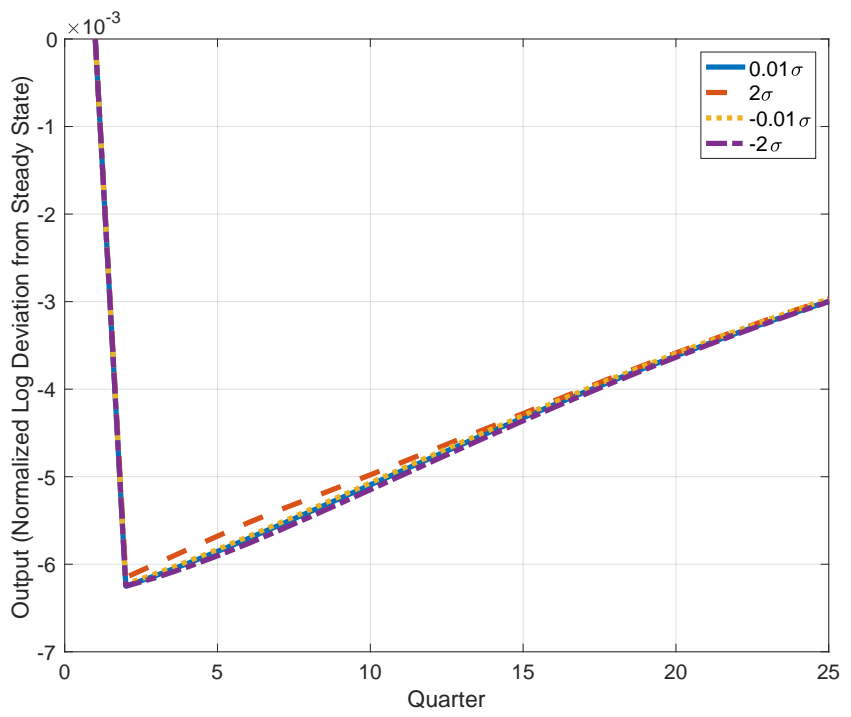

Figure 6: Normalized impulse responses for small/large positive/negative investmentspecific shocks

time, correlated either perfectly positively or perfectly negatively. We can then compare the IRFs to those from taking the linear combination of the IRFs to the two shocks individually.
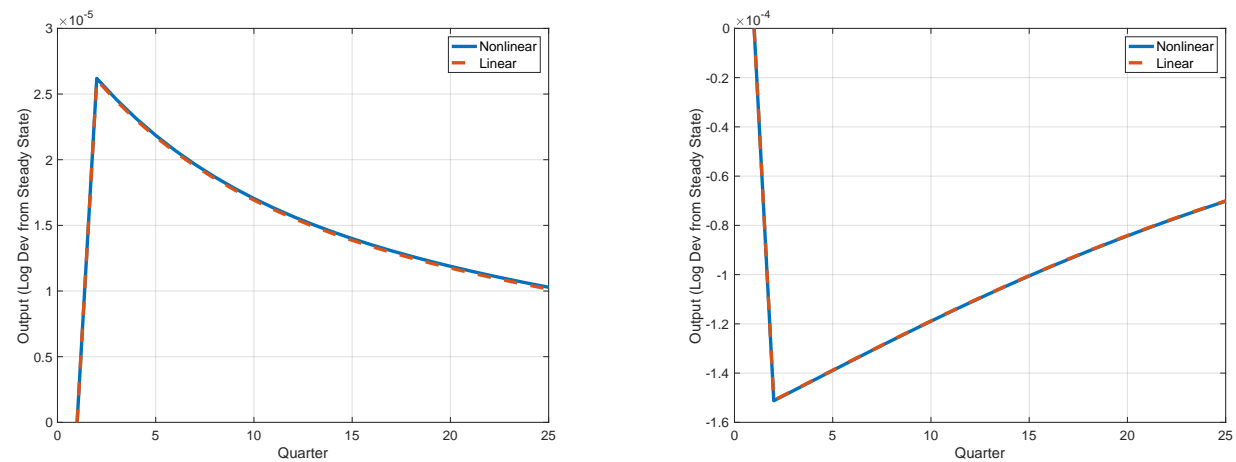

Figure 7: Differential impulse responses for correlated shocks.

Clearly, from inspecting Figure 7 there is very little sign of departure from linearity here as well. 


\subsubsection{Policy: Ricardian non-equivalence and demand-determined output}

In the model above, policy would have nontrivial effects relative to the corresponding representative-agent economy. This is perhaps a surprise to some, as it is often claimed that the model in Krusell and Smith (1998) "shows" that the distribution (almost) does not matter for outcomes. The quotation marks are used here because the opposite is in fact shown in the same paper. In the case where all consumers have the same discount factor the distribution (almost) does not matter for outcomes but in the case with discountfactor heterogeneity the distribution does matter. Moreover, the case where it matters is the quantitatively reasonable case in the sense that it matches the empirical wealth distribution well, whereas the case without discount-factor heterogeneity does not. The present model, though not featuring discount-factor heterogeneity, also features significant wealth inequality and gives the distribution a more prominent role, largely because the dynamic nature of idiosyncratic shocks is different here. ${ }^{20}$ Thus it will give policy a nontrivial role.

The purpose of the present section is to show that our method makes policy very straightforward to study - it does not add numerical complication. In particular, we show how it is straightforward to compute equilibria where policy follows a rule. The class of such rules is very large and we specify two very simple fiscal rules for illustration only. We also change the model somewhat by introducing an externality: we allow for aggregate productivity to depend on contemporaneous aggregate consumption. A key reason for this addition is that it makes the model more challenging to solve: it makes it necessary to guess on two paths to solve for the transitional equilibrium. ${ }^{21}$ We show that our method continues to work very well.

We specify the functional form for the demand externality $\phi(c)$ as follows:

$$
\phi(c)=\left(c-\kappa_{c}\right)^{\vartheta},
$$

\footnotetext{
${ }^{20} \mathrm{An}$ additional reason is that the utility function over consumption and hours employed here does not admit aggregation even under complete markets.

${ }^{21}$ The externality also gives policy an additional role, but that is not our focus here.
} 
where we set $\vartheta=0.2$ and $\kappa_{c}=0.3 C_{s s}$. We think of this externality as a reduced form for the type of demand-determined search productivity shocks modeled in, e.g., Bai et al. (2014). In the present paper the externality leads to a market failure, unlike in the Bai et al. paper, where the search process, which is competitive, leads to efficient outcomes. We conjecture that undirected search would generate features similar to the economy we consider here.

In this version of the model, knowing the capital-labor ratio is not sufficient for solving the household problem, because we need to know, in addition, aggregate consumption to determine the factor prices that the households face. We therefore need to shoot on an additional aggregate sequence and for this we choose aggregate consumption, $c_{t}$. The algorithm for computing transitions laid out in the section above is modified to update both the guess for the capital-labor ratio and aggregate consumption, but is otherwise unchanged (i.e., conditional on those conjectured prices and the productivity shock, we solve the household problem backwards, then simulate forward, check market clearing - for capital and hours, and hence consumption — and update). ${ }^{22}$

We also consider a policy that stabilizes aggregate consumption. The government sets the lump-sum transfer according to

$$
T=-c+0.05 b,
$$

where $c$ is aggregate consumption and $b$ is the level of government debt (so negative values of $b$ imply that the government is saving). This formulation stabilizes aggregate consumption, but also ensures long-run budget balance by responding also to the level of government debt.

Before we display the results for our main endogenous variables, let us illustrate the sense in which shooting on two sequences (the capital-labor ratio and consumption) is necessary in this economy. To this end, Figures 8 and 9 compare equilibrium wages over time to those that would have materialized without movements in the demand externality.

\footnotetext{
${ }^{22}$ We find that the our algorithm converges quickly when beginning with the RA model path as an initial guess despite the fact that we are now guessing on two sequences.
} 
Thus, for each aggregate shock scenario, the difference between the curves is a measure of how much a consumer would go wrong by predicting the wage solely based on the capitallabor ratio and the neutral productivity shock, hence ignoring the externality movements. We take some comfort in the fact that the gap is substantial and, thus, that in this version of the model shooting on two, as opposed to only one, sequence, is not only necessary from a conceptual perspective but also important in a quantitative sense.

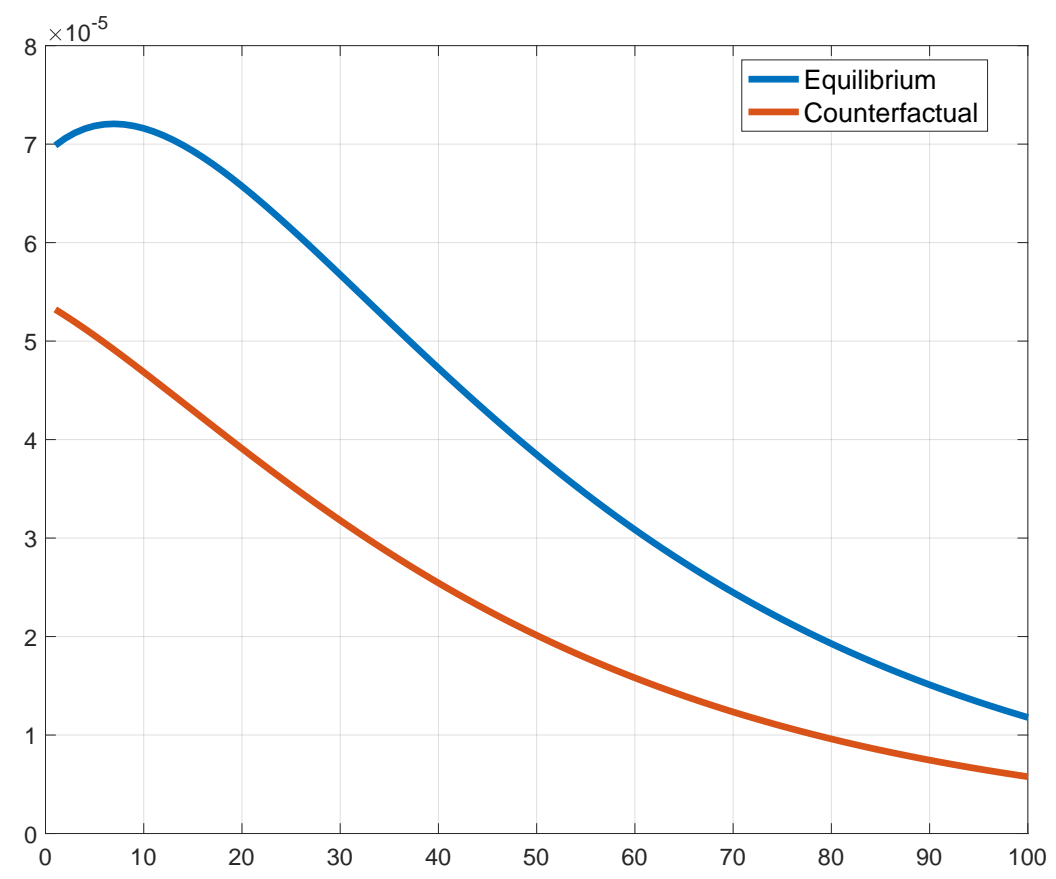

Figure 8: Wages in equilibrium vs. net of externalities, neutral shock.

The impulse responses for the economy with and without the policy are plotted in Figures 10 and 11.

We see that there is stabilization under the transfer policy. Note that the representativeagent version of the present economy would make lump-sum transfers completely ineffective because of Ricardian Equivalence. Under incomplete markets, transfers do influence aggregates as they involve redistribution across households with different marginal propen- 


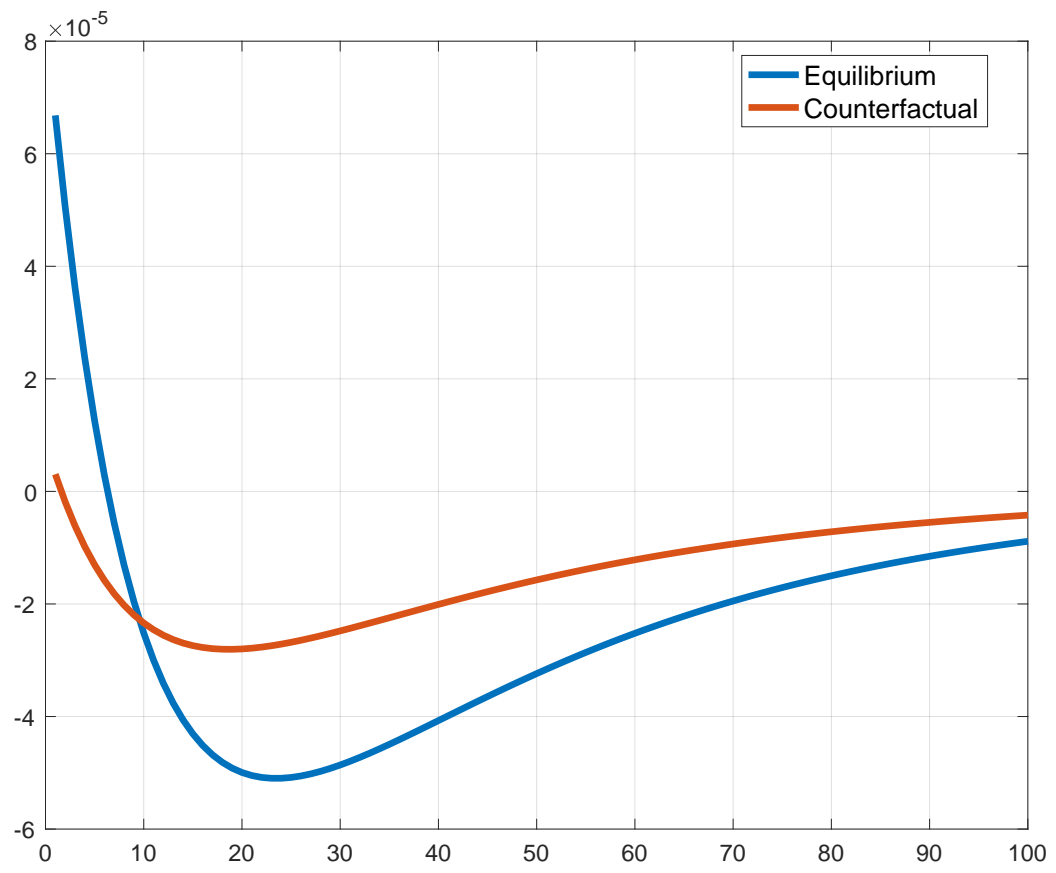

Figure 9: Wages in equilibrium vs. net of externalities, investment-specific shock. 

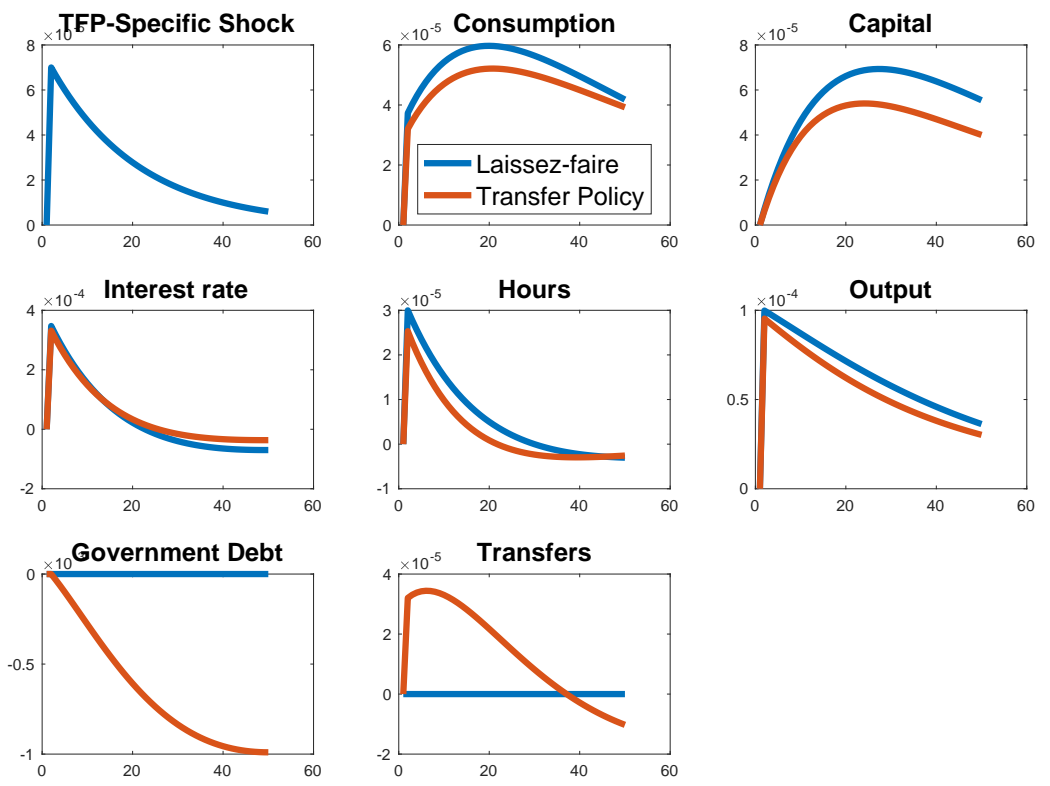

Figure 10: Impulse response to neutral shock for the HA economy with and without deficit-financed transfers. 

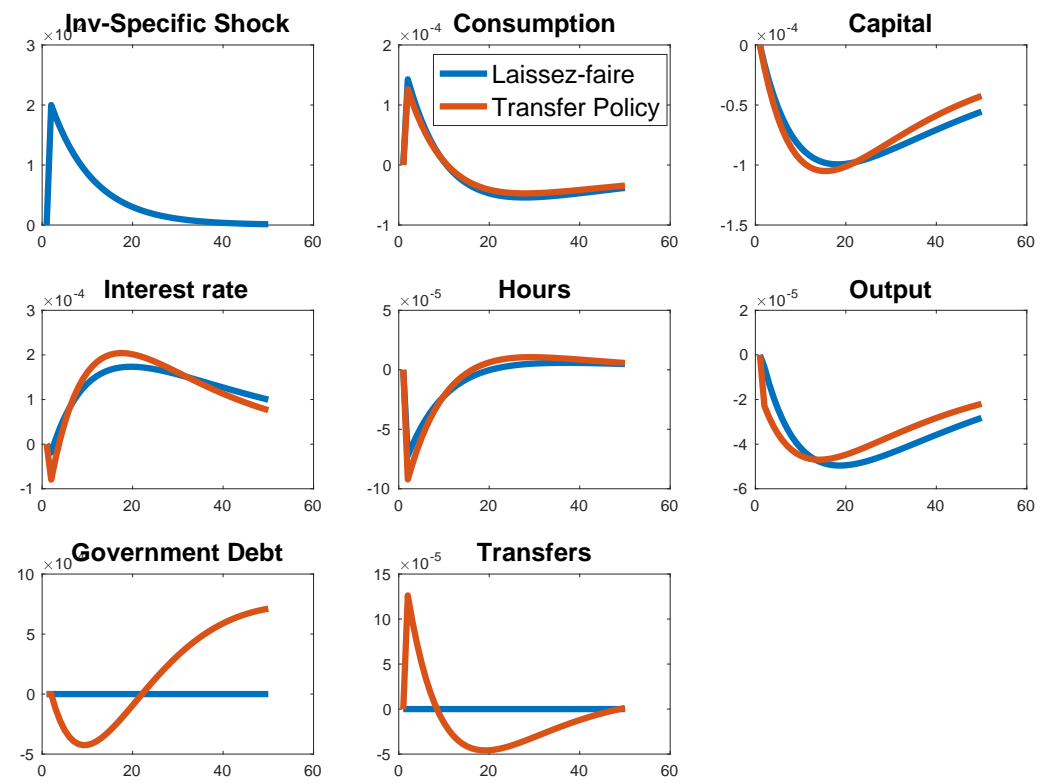

Figure 11: Impulse response to investment-specific shock for the HA economy with and without deficit-financed transfers. 
sities to consume and work.

In addition, we simulate the two versions of the model under recurring aggregate shocks using our method. The correlation tables are reported in Table 4 . We find that under the deficit-financed transfer policy, aggregate consumption is significantly stabilized relative to laissez-faire.

Table 4: Correlations between variables - HA economy with externality

\begin{tabular}{cccccccccc}
\hline$z$ & $q$ & $y$ & $c$ & $i$ & $h$ & $r$ & $w$ & HtM & Gini \\
\hline \hline \multicolumn{2}{l}{ Laissez-faire } & & & & & & & & \\
\hline 1.000 & -0.021 & 0.793 & 0.544 & 0.537 & 0.401 & 0.416 & 0.704 & -0.332 & -0.386 \\
-0.021 & 1.000 & -0.237 & 0.258 & -0.854 & -0.830 & 0.269 & 0.000 & 0.365 & 0.412 \\
0.793 & -0.237 & 1.000 & 0.823 & 0.595 & 0.269 & -0.223 & 0.958 & -0.813 & -0.855 \\
0.544 & 0.258 & 0.823 & 1.000 & 0.041 & -0.325 & -0.387 & 0.951 & -0.745 & -0.746 \\
0.537 & -0.854 & 0.595 & 0.041 & 1.000 & 0.920 & 0.014 & 0.345 & -0.454 & -0.523 \\
0.401 & -0.830 & 0.269 & -0.325 & 0.920 & 1.000 & 0.289 & -0.018 & -0.087 & -0.155 \\
0.416 & 0.269 & -0.223 & -0.387 & 0.014 & 0.289 & 1.000 & -0.318 & 0.681 & 0.655 \\
0.704 & 0.000 & 0.958 & 0.951 & 0.345 & -0.018 & -0.318 & 1.000 & -0.818 & -0.842 \\
-0.332 & 0.365 & -0.813 & -0.745 & -0.454 & -0.087 & 0.681 & -0.818 & 1.000 & 0.987 \\
-0.386 & 0.412 & -0.855 & -0.746 & -0.523 & -0.155 & 0.655 & -0.842 & 0.987 & 1.000 \\
\hline \hline Deficit-financed transfers & & & & & & & \\
\hline 1.000 & -0.021 & 0.796 & 0.026 & 0.413 & 0.221 & 0.458 & 0.718 & -0.657 & -0.367 \\
-0.021 & 1.000 & -0.311 & 0.400 & -0.902 & -0.835 & 0.286 & -0.011 & -0.282 & 0.029 \\
0.796 & -0.311 & 1.000 & 0.289 & 0.523 & 0.188 & -0.142 & 0.935 & -0.635 & -0.746 \\
0.026 & 0.400 & 0.289 & 1.000 & -0.476 & -0.717 & -0.528 & 0.549 & -0.528 & -0.507 \\
0.413 & -0.902 & 0.523 & -0.476 & 1.000 & 0.921 & 0.059 & 0.192 & 0.063 & -0.098 \\
0.221 & -0.835 & 0.188 & -0.717 & 0.921 & 1.000 & 0.274 & -0.172 & 0.310 & 0.195 \\
0.458 & 0.286 & -0.142 & -0.528 & 0.059 & 0.274 & 1.000 & -0.242 & -0.041 & 0.418 \\
0.718 & -0.011 & 0.935 & 0.549 & 0.192 & -0.172 & -0.242 & 1.000 & -0.749 & -0.818 \\
-0.657 & -0.282 & -0.635 & -0.528 & 0.063 & 0.310 & -0.041 & -0.749 & 1.000 & 0.485 \\
-0.367 & 0.029 & -0.746 & -0.507 & -0.098 & 0.195 & 0.418 & -0.818 & 0.485 & 1.000 \\
\hline \hline
\end{tabular}

\section{Concluding remarks}

We first sum up by pointing to our main findings: we present a simple numerical linearization method for heterogeneous-agent models with aggregate uncertainty and we find that it works very well in a standard RBC setting with neutral and investment-specific AR(1) technology shocks. We also look at a model with a consumption externality and government transfer policy, both illustrating how easy it is to examine the effects of eco- 
nomically relevant policy rules in our economy and how the method works well also when there are nontrivial market-clearing conditions each period. The tentative conclusion from our analysis here is that it would be entirely feasible to extend our methods to more complex settings; an example of such a setting is the kind of model studied by Smets and Wouters (2003), where there are frictions in price and wage setting, some additional real features to those considered here (such as consumption habits), and seven shocks. Given that one would solve for impulse responses to each shock individually, the inclusion of more shocks is not cumbersome: computing impulse responses to seven shocks is not much more time-consuming to the case of two shocks that we considered here.

We must also remind the reader that the only nontrivial tool necessary for implementing our solution method is value-function iteration. Value-function iteration is necessary for solving for the steady state and it is also the key tool in solving for the transition equilibrium. When it comes to what particular value-function iteration to choose, we are agnostic. However, we should note that using the endogenous grid point method in the transitional equilibrium case does allow to avoid any root finding or numerical optimization in the backsolve of the household decisions. One can also, alternatively, use methods based on policy-function iteration: our basic approach is equally applicable to that case.

It is obviously important to be able to solve for a transition path and it may be that there are settings for which this is significantly more demanding. As the techniques used in solving for transition paths could probably developed further-be made more stable as well as faster - we hope that this will not be a significant obstacle. Auclert and Rognlie (2017) propose a quasi-Newton method for computing transitions in heterogenous-agent economies that offers a promising step in this direction. ${ }^{23}$

Of course, our approach of using numerical linearization to solve for equilibria relies on nonlinearities not being important in the model at hand. Although this is a clear weakness, it is an integral part of the procedure we propose here to examine to what extent the equilibrium is "scalable", i.e., linear. Thus, if one finds that scalability is not

\footnotetext{
${ }^{23}$ In their application they compute an approximate Jacobian to the transitional system by solving a relaxed version of the household problem and then take Newton steps. They show that the their method is stable and efficient, and converges rapidly in their application.
} 
satisfied, the model's behavior is fundamentally more non-linear and other methods will have to be used, such as those offered in Krusell and Smith (1998). Finding models that are not approximately linear may be challenging, however, as much as such models could enhance our understanding of some real-world phenomena. Our scalability check seems a reasonable and challenging first hurdle to pass in the hunt for such models.

It should also be emphasized that our method, in placing MIT shocks and impulseresponse analysis at center stage, is sequential in nature, as opposed to recursive, like most other approaches. Sequentiality allows us to eliminate the complications introduced by infinite-dimensional (and typically uncountable) state vectors and functions of these state vectors by replacing them by sequences that, in the numerical application, are finite. For example, when one goes from solving an Aiyagari model for a steady state - in which no aggregate state variable is needed in the individual's dynamic programming problemto solving for a transition path for the same economy, one only adds one state variable, namely, time. The sequential nature of impulse responses also lends itself to inspecting the intuitive mechanisms of the model. In models with aggregate uncertainty and a discrete number of shocks, such as Krusell and Smith (1998) or Krusell, Mukoyama, Rogerson, and Şahin (2017), impulse responses are not a natural element of the mechanism inspection toolbox so it becomes harder to understand the model's conditional properties.

Models based on analytical linearization tend to come with an analysis of the stability properties of the dynamic system the model leads to (as in Blanchard and Kahn, 1980). In our case, no stability characterization is offered: we solve for a transition path and we do not characterize its uniqueness nor whether there are local explosive paths. To the extent there is a indeterminate set of stable paths, however, one would think that the iteration over price paths would have poor convergence properties; in any case, determinacy issues must be left for future research. ${ }^{24}$

Compared to the methods in the literature for solving heterogeneous-agent models, a disadvantage of the present method is that it does not offer a metric of fit. Instead it

\footnotetext{
${ }^{24}$ For a discussion of price-level determinacy in heterogenous-agent models in response to MIT shocks see Hagedorn, Manovskii and Mitman (2017) who apply the theoretical results of Hagedorn (2017) to a heterogenous-agent New Keneysian model.
} 
assumes that linearization works and proceeds based on this assumption. The assumption, we argue, can be tested to some extent with scalability checks, and hopefully one is reassured at this point that linearization offers a good approximation. In contrast, models based on recursive techniques, whether linear or nonlinear, can, when they are simulated, offer a test in the form of a comparison between the simulated path of aggregate variables appearing in an individual's decision problem and the perceptions of this behavior assumed in his decision problem. Thus a goodness-of-fit measure, such as an $\mathrm{R}^{2}$, can be computed. ${ }^{25}$ In sum, there are pros and cons with our approach but we hope that it can be of value, mainly because of its simplicity and ties to impulse-response analysis, in a range of interesting applications.

\section{References}

Ahn, S., Kaplan, G., Moll, B., Winberry, T., and Wolf, C. (2017). When Inequality Matters for Macro and Macro Matters for Inequality. In NBER Macroeconomics Annual 2017, volume 32. University of Chicago Press.

Aiyagari, S. R. (1994), "Uninsured Idiosyncratic Risk and Aggregate Saving", Quarterly Journal of Economics 109: 659-684.

Alesina, A., and Rodrik, D. (1994) "Distributive politics and economic growth", The quarterly journal of economics 109(2), 465-490.

Auclert, A. and Rognlie, M. (2017) "Inequality and Aggregate Demand", Working Paper.

Bai, Y., J.-V. Ríos Rull and K. Storesletten (2012), "Demand Shocks as Productivity Shocks", Working Paper.

Blanchard, O. and Kahn, C. M. (1980). "The solution of linear difference models under rational expectations", Econometrica 1305-1311.

\footnotetext{
${ }^{25}$ Having said this, the majority of applied papers in quantitative business-cycle modeling are written without ever checking whether linearity is a good approximation: they propose models that are fundamentally non-linear and then just go ahead and solve them using Dynare's linearization algorithm.
} 
Carroll, C.D., (2006). "The method of endogenous gridpoints for solving dynamic stochastic optimization problems", Economics letters, 91(3), pp.312-320.

Childers, D. (2017). On the Solution and Application of Rational Expectations Models with Function-Valued States. Unpublished manuscript.

Downs, A. (1957) "An economic theory of political action in a democracy", Journal of Political Economy, 65(2), 135-150.

Greenwood, J., Hercowitz, Z., and Krusell, P. (2000) "The role of investment-specific technological change in the business cycle", European Economic Review, 44(1), 91115.

Den Haan, W. J. (2010), "Assessing the Accuracy of the Aggregate Law of Motion in Models with Heterogeneous Agents

Den Haan, W. J., Judd, K. L., and Juillard, M. (2010). Computational suite of models with heterogeneous agents: Incomplete markets and aggregate uncertainty. Journal of Economic Dynamics and Control, 34(1), 1-3. ", Journal of Economic Dynamics and Control 34: 79-99.

Hagedorn, M. (2017). "A Demand Theory of the Price Level", Working Paper.

Hagedorn, M., Manovskii, I. and Mitman, K. (2017). "The Fiscal Multiplier", Working Paper.

Huggett, M. (1993), "The Risk-Free Rate in Heterogeneous-Agent Incomplete-Insurance Economies", Journal of Economic Dynamics and Control 17: 953-969.

Imrohoroglu, A. (1989), "Cost of Business Cycles with Indivisibilities and Liquidity Constraints", Journal of Political Economy 97: 1364-1383.

Johnson, David S., Jonathan A. Parker, and Nicholas S. Souleles. "The Response of Consumer Spending to the Randomized Income Tax Rebates of 2001." Bureau of Labor Statistics, Princeton University, and University of Pennsylvania (February) (2004). 
Judd, K. and Guu, S. M. (1997). "Asymptotic methods for aggregate growth models", Journal of Economic Dynamics and Control, 21(6), 1025-1042.

Khan, A. and J. K. Thomas (2008), Idiosyncratic Shocks and the Role of Noncon- vexities in Plant and Aggregate Investment Dynamics, Econometrica 76: 395-436

King, R. G., Plosser, C. I., and Rebelo, S. T. (1988). Production, growth and business cycles: I. The basic neoclassical model. Journal of monetary Economics, 21(2-3), 195-232.

King, R. G., Plosser, C. I., and Rebelo, S. T. (2002). Production, growth and business cycles: Technical appendix. Computational Economics, 20(1), 87-116.

Kopecky, K. and Suen R. (2010). "Finite state Markov-chain approximations to highly persistent processes", Review of Economic Dynamics, Vol 13, p 701-714

Krueger, D., Mitman K. (2016), and Perri, F. "Macroeconomics and Household Heterogeneity", Handbook of Macroeconomics, Vol. 2, 843-921.

Krusell, P., and Ríos-Rull, J. V. (1999) "On the size of US government: political economy in the neoclassical growth model", American Economic Review, 1156-1181.

Krusell, P. and A. Smith Jr. (1997), "Income and Wealth Heterogeneity, Portfolio Choice, and Equilibrium Asset Returns", Macroeconomic Dynamics 1: 387-422.

Krusell, P., and A. A. Smith Jr. (1998), "Income and Wealth Heterogeneity in the Macroeconomy", Journal of Political Economy 106: 867-896.

Krusell, P., Mukoyama, T., Rogerson, R., and Şahin, A. (2017). Gross worker flows over the business cycle. American Economic Review 107:11, 3447-3476.

Krusell, P, T. Mukoyama and A. Şahin (2010), "Labor-market matching with precautionary savings and aggregate fluctuations", Review of Economic Studies 77: 1477-1507.

Krusell, P., Mukoyama, T., Şahin, A., and Smith, A. A. (2009). Revisiting the welfare effects of eliminating business cycles. Review of Economic Dynamics, 12(3), 393-404. 
Kydland, F. E., and E. C. Prescott (1982) "Time to build and aggregate fluctuations", Econometrica $1345-1370$.

Meltzer, A. H., and Richard, S. F. (1981) "A rational theory of the size of government", Journal of political Economy 89(5), 914-927.

Misra, K., and Surico, P. (2014) "Consumption, income changes, and heterogeneity: Evidence from two fiscal stimulus programs." American Economic Journal: Macroeconomics 6, no. 4: 84-106.

Persson, T., and Tabellini, G. (1994) "Is inequality harmful for growth?", The American Economic Review, 600-621.

Piketty, T. (2014), Capital in the Twenty-First Century, Belknap Press, Cambridge, MA.

Pissarides, C. A. (1985). Short-run equilibrium dynamics of unemployment, vacancies, and real wages. The American Economic Review, 75(4), 676-690.

Reiter, M. (2009). Solving heterogeneous-agent models by projection and perturbation. Journal of Economic Dynamics and Control, 33(3), 649-665.

Reiter, M. (2010). Approximate and Almost-Exact Aggregation in Dynamic Stochastic Heterogeneous-Agent Models, IHS WP 259.

Ríos-Rull, J.-V. (2001), "Computation of Equilibria in Heterogeneous Agent Models", in Marimon, R. and A. Scott, eds., Computational Methods for the Study of Dynamic Economies: An Introduction, Oxford University Press, 238280.

Schmitt-Grohe, S., and Uribe, M. (2004). Solving dynamic general equilibrium models using a second-order approximation to the policy function. Journal of economic dynamics and control, 28(4), 755-775.

Sims, C. A. (1980). Macroeconomics and reality. Econometrica, 1-48. 
Smets, F. and Wouters, R., (2003). "An estimated dynamic stochastic general equilibrium model of the euro area", Journal of the European economic association, 1(5), pp.1123-1175.

Taylor, J. B., and Uhlig, H. (1990). Solving nonlinear stochastic growth models: a comparison of alternative solution methods. Journal of Business \& Economic Statistics, $8(1), 1-17$. 